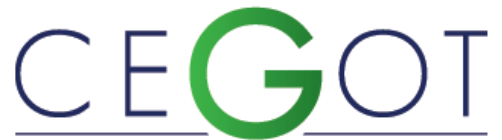

Centro de Estudos de Geografia e Ordenamento do Território
MoREIRA, JANAÍNA

Universidade Estadual Paulista Júlio de Mesquita Filho, Faculdade de Ciências e Tecnologia, Departamento de Geografia

Rua Roberto Simonsen, 305, 19060-900, Presidente Prudente (SP), Brasil janainamoreira1991@hotmail.com

\author{
AMORIM, MARGARETE \\ Universidade Estadual Paulista Júlio de Mesquita Filho, \\ Faculdade de Ciências e Tecnologia, Departamento de \\ Geografia \\ Rua Roberto Simonsen, 305, 19060-900, Presidente Prudente (SP), Brasil \\ mccta@fct.unesp.br \\ GARcía, FeliPE \\ Departamento de Geografía, Universidad Autónoma de Madrid \\ (UAM) \\ Ciudad Universitaria de Cantoblanco, C/ Francisco Tomás y Valiente, Madrid \\ 28049, España \\ felipe.fernandez@uam.es
}

\title{
Análisis de la intensidad y evolución horaria de las islas de calor y seca en ambiente tropical, Brasil
}

Análise da intensidade e evolução horária das ilhas de calor e seca em ambiente tropical, Brasil Analysis of intensity and hourly evolution of the heat and dry islands in a tropical environment, Brazil

Referência: Moreira, Janaína; Amorim, Margarete; García, Felipe (2019). Análisis de la intensidad y evolución horaria de las islas de calor y seca en ambiente tropical, Brasil. Revista de Geografia e Ordenamento do Território (GOT), n. ${ }^{\circ} 17$ (junho). Centro de Estudos de Geografia e Ordenamento do Território, p. 151-178, dx.doi.org/10.17127/got/2019.17.007

\section{RESUMEN}

Este artículo tiene como objetivo analizar la intensidad y la evolución horaria de la isla de calor y seca en Penápolis, una ciudad pequeña del noroeste de São Paulo, Brasil de acuerdo con los diferentes tipos de tiempo. Los resultados indicaron la formación de una isla de calor urbana de las $19 \mathrm{~h}$ hasta las $9 \mathrm{~h}$ e intensidad máxima de $3,5^{\circ} \mathrm{C}$ y una isla seca de las $23 \mathrm{~h}$ hasta las $9 \mathrm{~h}$ e intensidad máxima de $-9,4 \%$. Las islas de calor y seca actuaron concomitantemente en la zona urbana, principalmente en días de estabilidad atmosférica (vientos débiles y sin precipitación). Además, se resalta que ambas también tuvieron sus intensidades máximas en diciembre (verano), que indica una situación agravante, una vez que las molestias térmicas en el ambiente tropical en esa estación fueron potenciadas por estos fenómenos.

Palabras clave: Clima urbano. Isla de calor urbana. Temperatura del aire. Humidad relativa del aire.

\section{ABSTRACT}

This paper aims to analyze the intensity and hourly evolution of heat and dry islands in Penápolis, a small city in the Northwest region of São Paulo State, Brazil, according to 
different synoptic conditions. Results indicated the formation of a urban heat island from $7 \mathrm{pm}$ to 9am, with maximum intensity of $3.5^{\circ} \mathrm{C}$, and a dry island from $11 \mathrm{pm}$ to 9am, with maximum intensity of $-9.4 \%$. The heat and dry islands acted concomitantly in the urban area, especially during days with stable weather conditions (light winds and no precipitation). In addition, we emphasize that both islands showed maximum intensities in December (summer), which indicates an aggravating situation, once the thermal discomfort in the tropical environment in this season were potentialized by these phenomena.

Keywords: Urban climate. Urban heat island. Air temperature. Relative humidity.

\section{RESUMO}

Este artigo tem como objetivo analisar a intensidade e a evolução horária da ilha de calor e seca em Penápolis, uma cidade pequena do noroeste do estado de São Paulo, de acordo com os diferentes tipos de tempo. Os resultados indicaram a formação de uma ilha de calor urbano das $19 \mathrm{~h}$ às $9 \mathrm{~h}$ e intensidade máxima de $3,5^{\circ} \mathrm{C}$ e uma ilha seca das $23 \mathrm{~h}$ às $9 \mathrm{~h}$ e intensidade máxima de $-9,4 \%$. A ilha de calor e seca atuaram concomitantemente na área urbana, principalmente em dias de estabilidade atmosférica (ventos fracos e sem precipitação). Além disso, destaca-se que ambas também tiveram suas intensidades máximas em dezembro (verão), o que indica uma situação agravante, uma vez que os desconfortos térmicos no ambiente tropical nessa estação foram potencializados por esses fenômenos.

Palavras-chave: Clima urbano. Ilha de calor urbana. Temperatura do ar. Umidade relativa do ar.

\section{Introducción}

La ciudad se consolidó como lugar de vivienda de gran parte de la población mundial en el siglo XX. Según la ONU, desde 1990 el mundo ha visto un incremento en la concentración de la población en las áreas urbanas. Esta tendencia no es nueva y ha sido marcada por un notable crecimiento medio anual en los números absolutos de habitantes urbanos, pasando de 57 millones entre 1990-2000 a 77 millones en 2010-2015. En 1990, el 43\% (2,3 mil millones) de la población mundial vivía en las ciudades, en 2015 este valor creció a 54\% (4 mil millones) (ONU-HABITAT, 2016) y se estima que en el 2030 el $60 \%$ de la población mundial vivirá en las ciudades (ONUBR, 2012).

Este aumento puede asociarse a los procesos de urbanización más recientes ocurridos en algunos países, como los ubicados en América Latina y el Caribe, que entre 1950 y 1990 han visto sus poblaciones urbanas crecer del $40 \%$ al $70 \%$. Actualmente, esta región posee una tasa de urbanización de casi el $80 \%$, la más elevada del planeta, superando a la registrada en 
los denominados países desarrollados. Este "boom" urbano en 40 años tuvo un ritmo tan acelerado que puede ser calificado como período de "explosión urbana" (ONU-HABITAT, 2012).

En Brasil, este fenómeno se produce principalmente con la llegada de grandes empresas multinacionales, sobre todo industriales y por las profundas transformaciones de las zonas rurales con la concentración agraria, el monocultivo, la mecanización de la agricultura y la ausencia de políticas públicas de incentivo a la permanencia en el campo han provocado la migración masiva de la población rural hacia las zonas urbanas (SCARLATO, 2009).

Por lo tanto, la expansión de las áreas urbanas brasileñas fue motivada, sobre todo por el éxodo rural, que aceleró el crecimiento poblacional en los centros urbanos y la aparición de nuevas ciudades. Este rápido aumento de la cantidad de población urbana fue determinante para el agravamiento de los males urbanos, para las condiciones de vida y la actual configuración de las ciudades (SANTOS, 2009).

En las últimas décadas los problemas ambientales urbanos han sido el objeto de investigación de la comunidad académica y científica brasileña, la cual preocupada con el mantenimiento de la calidad de vida de la población, ha buscado ofrecer alternativas de planificación para el crecimiento urbano y acciones mitigadoras para amenizar los cuadros de degradación ambiental de áreas ya afectadas. Entre estas preocupaciones podemos destacar grandes avances en los estudios relacionados con la atmósfera, principalmente los relacionados al clima urbano (TARIFA, 1975; LOMBARDO, 1985; BRANDÃO, 1996; MENDONÇA, 1994; AMORIM, 2000), en gran parte basadas en la preposición teórica metodológica sistémica (MONTEIRO, 1976).

Las primeras investigaciones brasileñas se centraron en las grandes ciudades, entre ellas, se destacan São Paulo (LOMBARDO, 1985) y Rio de Janeiro (BRANDÃO, 1996). Por lo tanto, estudios recientes han diagnosticado modificaciones fuertes y prejudiciales en la atmósfera de ciudades medias y pequeñas (AMORIM, 2005, 2010; AMORIM e DUBREUIL, 2017). Investigaciones desarrolladas en ciudades de menos de 30 mil habitantes (RAMPAZZO e SANT'ANNA NETO, 2012; TEIXEIRA e AMORIM, 2016; PORANGABA e AMORIM, 2017), diagnosticaron significativas diferencias de temperatura, configurando la formación de islas 
de calor de magnitud moderada (entre $2^{\circ} \mathrm{C}$ y $4^{\circ} \mathrm{C}$ ) y fuerte (entre $4^{\circ} \mathrm{C}$ y $6^{\circ} \mathrm{C}$ ) (FERNÁNDEZ GARCÍA, 1996).

Penápolis ya fue contemplada con estudios de la atmosfera urbana hecho por Silva, Tommaselli y Amorim (2002), no cual a través de la instalación de 7 puntos fijos de coleta de temperatura e humidad durante el mes de julio de 1999 los autores han detectado diferencias significativas en la distribución de temperatura entre la área urbana y rural. Los resultados mostraron que el punto instalado en el centro urbano era lo de mayor temperatura en grande parte del día, con excepción del período de la tarde. A las $21 \mathrm{~h}$ en días de tiempo estable la diferencia térmica entre el punto del centro y de la área rural ha llegado a $8^{\circ} \mathrm{C}$ (SILVA; TOMMASELLI; AMORIM, 2002).

Así mismo, trabajos previos sobre ciudades brasileñas muestran que el crecimiento urbano produce un deterioro en la calidad ambiental (MENDONÇA, 2009) causado en parte por la intensificación de la isla de calor. Luego, partimos del supuesto de que el crecimiento urbano de los últimos años en Penápolis pudo haber acarreado en la intensificación del cuadro de incomodidad térmica causado por una isla de calor nocturna (OKE, 1982, 1987).

En este contexto, se observó la necesidad dar continuidad en el estudio de la atmosfera urbana de Penápolis-SP, pero ahora con el enfoque tanto en la isla de calor urbana cuanto en la isla seca. La humidad en la UCL (Urban Canopy Layer) es poco estudiada, por eso hay una dificultad de establecer parámetros generales para la isla seca. Cuando se trata ciudades pequeñas ubicadas en el ambiente tropical el número de pesquisas es aún más reducido (OKE et al., 2017).

Por lo tanto, este trabajo tiene como objetivo analizar la intensidad y la evolución horaria de la isla de calor y seca en ambiente tropical de acuerdo con los diferentes tipos de tiempo en Penápolis, São Paulo, Brasil. Para tanto, enfatizamos los estándares encontrados con el fin de proporcionar una contribución a los estudios futuros de la isla de calor y seca en las ciudades de clima tropical. 


\section{1. Área de estudio}

Ubicada en la región sudeste de Brasil, al noroeste del estado de São Paulo (Figura 1), Penápolis es un municipio con un área aproximada de $711 \mathrm{Km}^{2}$, altitud media de 416 metros y con una población estimada de 62.738 habitantes, siendo que el 95\% de la población son residentes en el área urbana (IBGE, 2017).

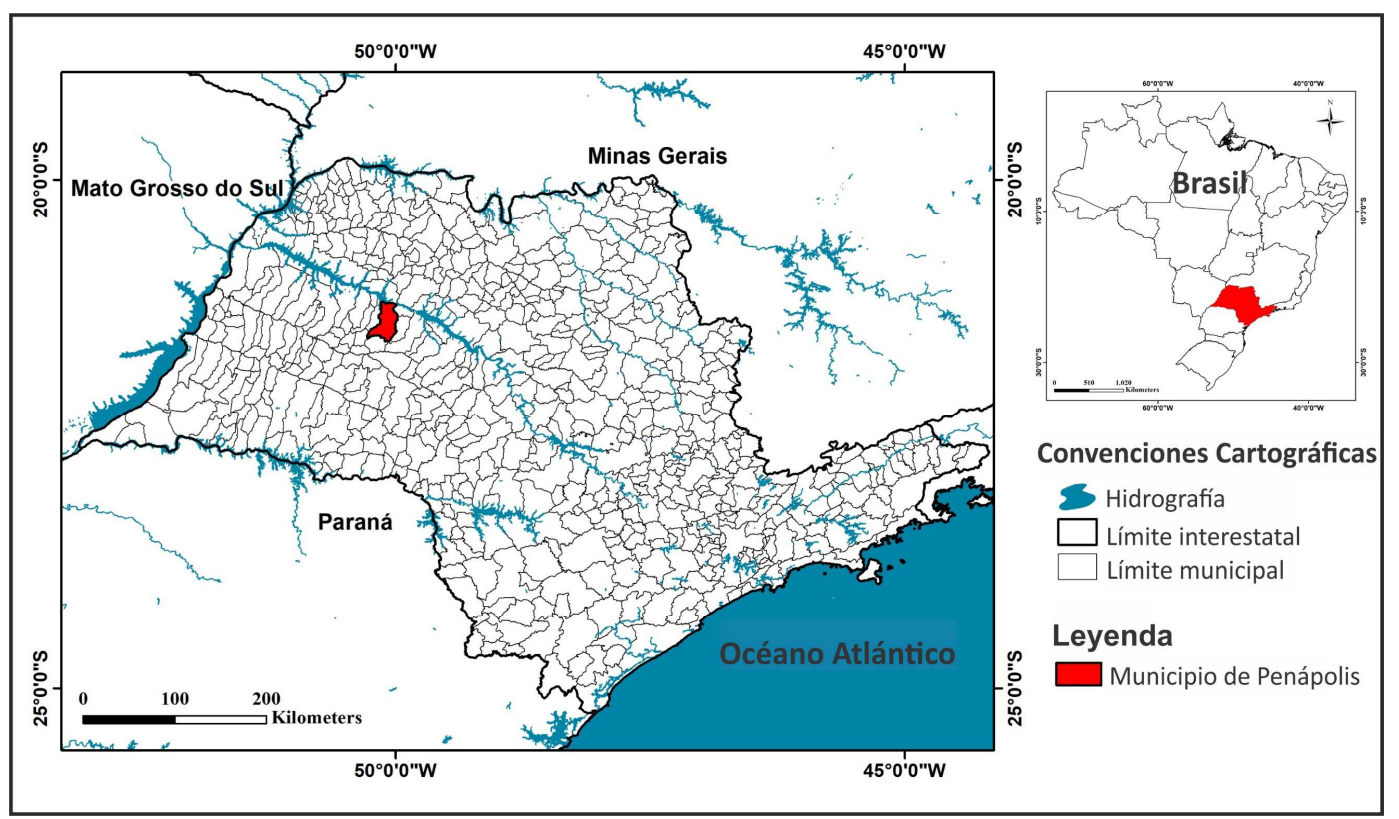

Figura 1 - Mapa de localización del municipio de Penápolis en el noroeste del estado de São Paulo, Brasil. Fuente: IBGE (Instituto Brasileiro de Geografia e Estatística) Organización: Elaborado por los autores.

El Estado de São Paulo, donde se ubica el municipio de Penápolis se caracteriza por el clima tropical, siendo un área de transición climática entre los sistemas tropicales y polares, con estaciones húmedas y secas bien definidas: verano cálido y lluvioso e invierno suave y seco.

La dinámica atmosférica de la zona es muy variada con la actuación de una gran cantidad de sistemas atmosféricos, casi todos los presentes en América del Sur. A menudo actúan en la región las masas Tropical Continental, Tropical Atlántica, Polar Atlántica y Ecuatorial Continental, además de la Zona de Convergencia de Humedad (ZCOU), Zona de Convergencia del Atlántico Sur (ZCAS), el Complejo Convectivo de Mesoescala (CCM), Cristas, Cavados y las líneas de Inestabilidad Tropical.

Las situaciones más favorables para la formación e intensificación de la isla de calor son las masas, principalmente Tropical Atlántica y Polar Atlántica que producen tiempo estable, sin 
lluvia y sin viento y con bastante radiación solar. En contrapartida, las islas tienen menor intensidad y/o dejan de existir cuando los sistemas de tiempo inestable actúan sobre la ciudad, como las ZCOU, ZCAS y las líneas de Inestabilidad Tropical.

La historia de ocupación del municipio está asociada al rápido proceso de ocupación vinculado a la implantación de la vía férrea Noroeste de Brasil y la ocupación de nuevas tierras para la cultura cafetera (MOREIRA e AMORIM, 2015). En lo que se refiere al perfil paisajístico, su área rural tiene como característica la presencia de plantaciones de caña de azúcar y pastizales. El área urbana se caracteriza por sectores de elevada y media densidad de edificación, vegetación arbórea ausente, de baja y media densidad y lotes pequeños. Estas características son encontradas, principalmente en los barrios del centro comercial antiguo y sus adyacencias y en los barrios residenciales populares.

\section{Materiales y métodos}

El análisis hecho en este estudio se ha basado en datos recogidos por dos puntos fijos (Figura 2). Uno de esos puntos fue ubicado en el área central de la ciudad caracterizado por un alto grado de edificaciones y el otro en el área rural del municipio (Figura 3), ambos con altitudes similares (433 metros en el punto urbano y 397 metros en el punto rural, sobre el nivel del mar). 


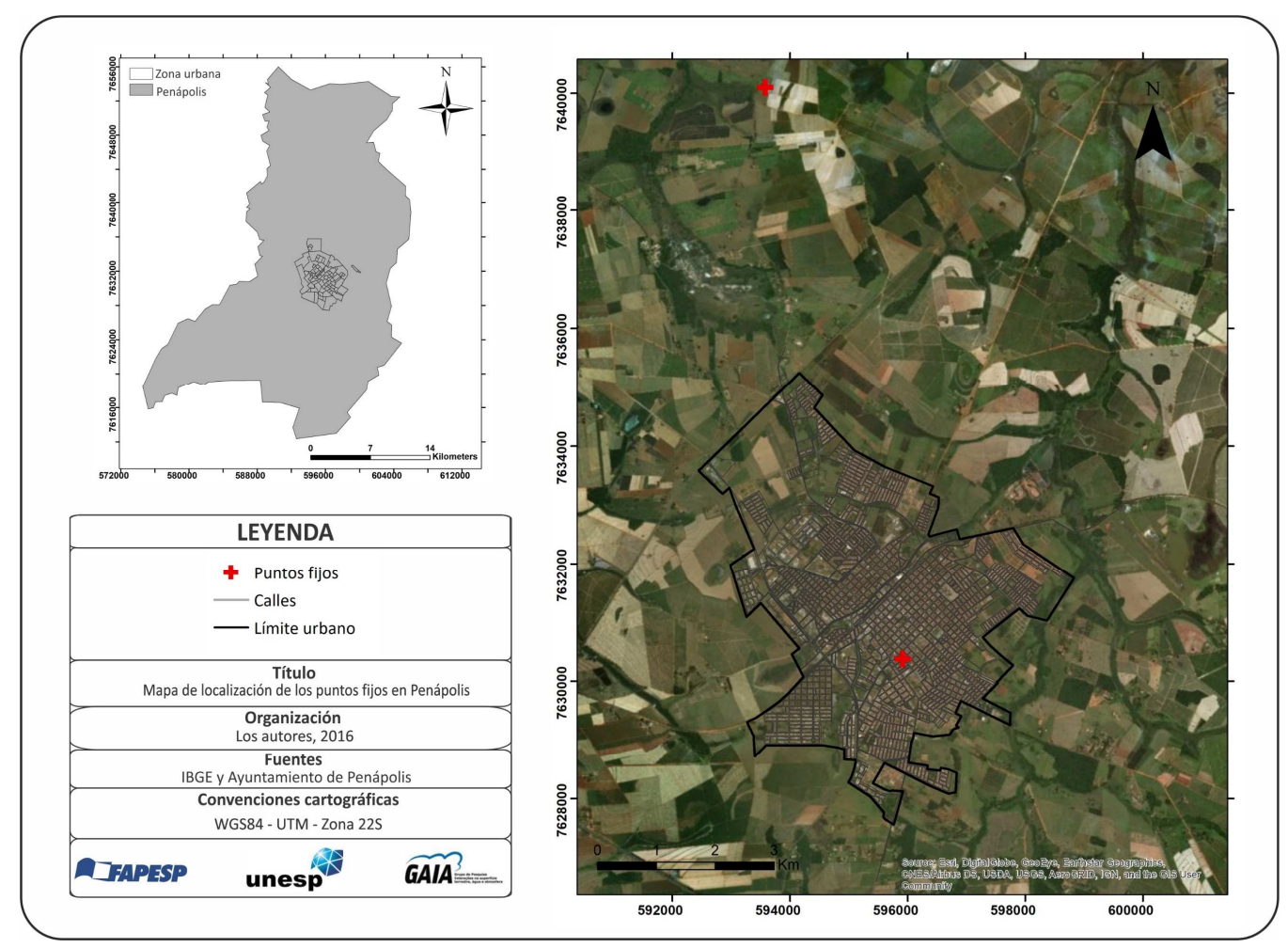

Figura 2 - Mapa de localización de los puntos fijos en Penápolis. Fuente: IBGE y Ayuntamiento de Penápolis. Organización: Elaborado por los autores.
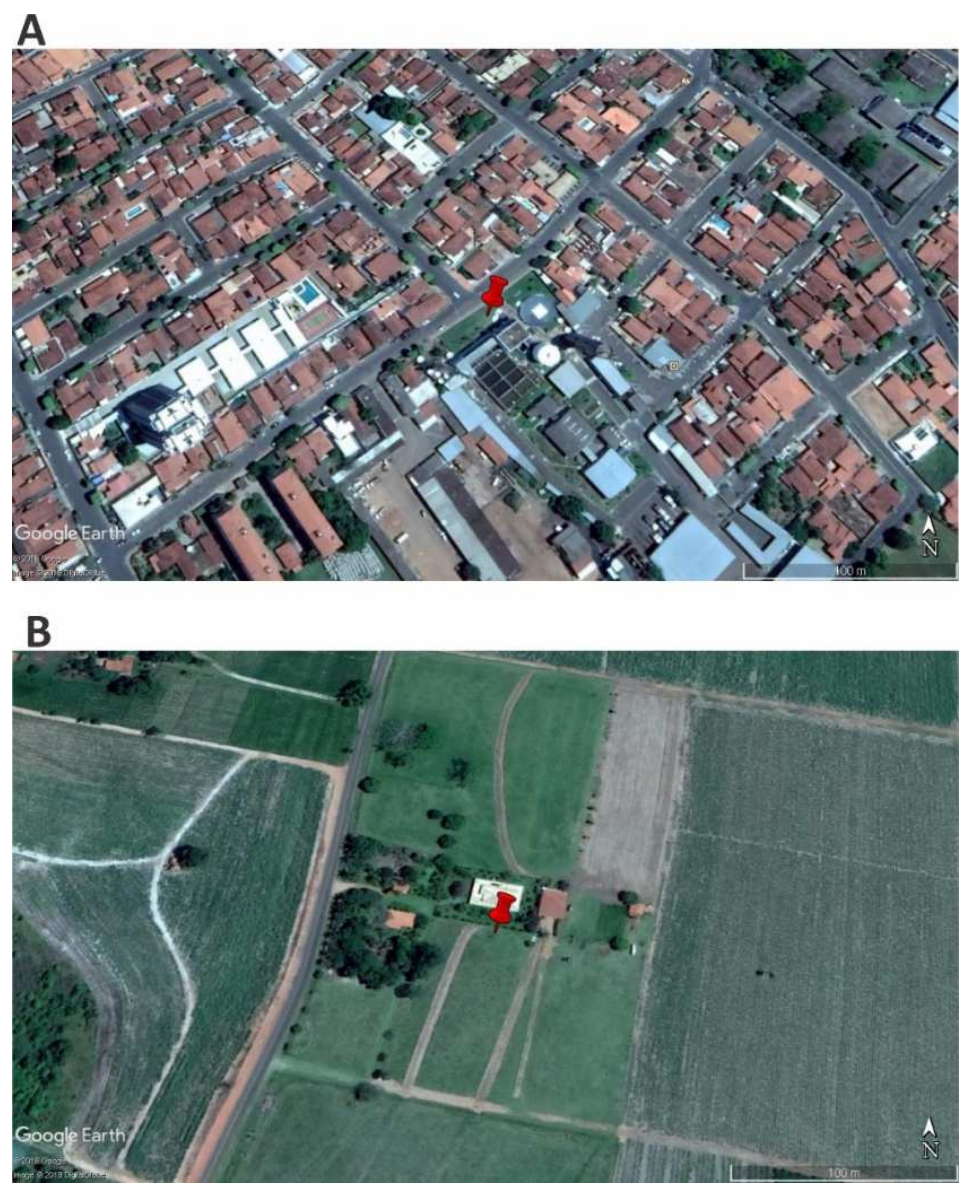

Figura 3 - En A punto urbano en B punto rural. Fuente: Google imágenes, 2016. 
Los datos fueron recolectados a través de sensores Humidity-temperature logger, de la marca ThermaData ${ }^{T M}$ y del modelo HTD D104505072 durante los meses de diciembre de 2014 y enero, junio y julio de 2015. Los sensores fueron colocados en abrigos meteorológicos Weather modelo SRS 100 pagoda de temperature and humidity radiation shield instalados en una altura media de $1,5 \mathrm{~m}$ del suelo.

Para el análisis de la isla de calor y seca en la ciudad de Penápolis fue realizado el tratamiento estadístico de los datos climáticos de temperatura $\left({ }^{\circ} \mathrm{C}\right)$ y humedad relativa $(\%)$ a partir de cálculos en el programa Excel ${ }^{1}$. Primeramente, fue realizado el tratamiento de los datos horarios generales (horas impares) de todos los días de las dos estaciones fijas, es decir, datos que no recibieron ningún tipo de filtro de acuerdo a las condiciones atmosféricas. Posteriormente, hemos hecho una filtración de los datos de días con y sin lluvia, y los días con y sin viento ${ }^{2}$. Para los días sin viento se consideraron las velocidades entre 0 y 2,9 m/s y para los días con viento velocidades iguales o superiores a 3,0 m/s. Este tipo de tratamiento de los datos se justifica por la influencia de las condiciones meteorológicas en la formación y la intensidad de la isla de calor urbana. La síntesis de los datos recogidos y analizados se puede observar en la tabla 1.

\begin{tabular}{c|c|c|c|c|c}
\hline Días/Tipo de tiempo & Generales & Con lluvia & Sin lluvia & Con viento & Sin viento \\
\hline № de días analizados & 123 & 34 & 89 & 75 & 48 \\
\hline Porcentaje (\%) & 100 & 27,64 & 72,35 & 60,97 & 39,02 \\
\hline
\end{tabular}

Tabla 1 -Síntesis de los datos recogidos y analizados de acuerdo con los diferentes tipos de tiempo Fuente: Elaborado por los autores.

Por lo tanto, a través de la utilización de la herramienta de filtro los días fueron tratados por separado - días con y sin lluvia, y también días con y sin viento. Además, fue utilizado las herramientas ordenar y subtotal con la activación de media para la extracción de los promedios de la temperatura y la humedad relativa por hora. Los resultados fueron colocados en nuevas hojas de cálculo para calcular las diferencias entre los puntos urbanos y rurales, y también para identificar la duración y la hora de máxima intensidad de la isla de calor.

\footnotetext{
${ }^{1}$ Excel - es marca registrada de Microsoft Coporation

${ }^{2}$ Se tomaron datos de viento de la Estación Meteorológica Automática, mantenida por el INMET (Instituto Nacional de Meteorología), ubicada en la ciudad de Lins (SP). Lins es distante $40 \mathrm{~km}$ de Penápolis.
} 
Estas informaciones fueron organizadas en tablas para comparar las diferencias existentes entre los tipos de tiempo y para verificar la influencia de estos en la intensidad de la isla de calor y seca.

La intensidad horaria de la isla de calor fue determinada a partir de la ecuación 1 (OKE et al., 2017):

$$
\Delta \mathbf{T u}-\mathbf{r}=\mathbf{T u}-\mathbf{T r}
$$

Siendo que:

$\Delta T u-r=$ intensidad de la isla de calor.

Tu= temperatura del aire en el área urbana.

$\mathrm{Tr}=$ temperatura del aire en el ambiente rural.

Cabe destacar que, el tratamiento de la isla seca ha seguido el mismo cálculo, lo que significa que la humedad relativa del aire de la zona rural fue extraída de la urbana.

Además, para observar la variación estacional se ha calculado el promedio de los meses de diciembre y enero, y de los meses de junio y julio para identificar las características de la isla de calor y seca de verano y de invierno, respectivamente. Por lo tanto, en una nueva hoja de cálculo, después de los cálculos de las intensidades de cada mes, fueron hechos los gráficos finales que tienen la intensidad, evolución y la duración de isla de calor y seca de las estaciones analizadas.

\section{Resultados}

\subsection{Intensidad y evolución horaria de la isla de calor y seca con base en los datos generales}

En la Tabla 2 se presentan la intensidad media máxima, la hora de la máxima y la duración de la isla de calor y seca en Penápolis. Los resultados demostraron que la intensidad de la isla de calor varió entre $2,2^{\circ} \mathrm{C}$ y $3,1^{\circ} \mathrm{C}$ en las estaciones analizadas, con máxima en enero y mínima en diciembre. Durante el verano la isla de calor tuvo mayor duración, siendo permanente en diciembre. En invierno, hubo una disminución presentando 15h de duración 
en ambos meses. Los horarios de máxima intensidad de las islas de calor han coincidido con los horarios nocturnos, sobre todo a las $23 \mathrm{~h}$ en enero y julio y a la $1 \mathrm{~h}$ en junio. Diciembre difiere de ese patrón con la máxima intensidad a las 9h de la mañana.

\begin{tabular}{c|c|c|c|c}
\hline Variables de la isla de calor & $\begin{array}{c}\text { Diciembre } \\
\text { (verano) }\end{array}$ & $\begin{array}{c}\text { Enero } \\
\text { (verano) }\end{array}$ & $\begin{array}{c}\text { Junio } \\
\text { (invierno) }\end{array}$ & $\begin{array}{c}\text { Julio } \\
\text { (invierno) }\end{array}$ \\
\hline Intensidad media máxima & $2,2^{\circ} \mathrm{C}$ & $3,1^{\circ} \mathrm{C}$ & $2,7^{\circ} \mathrm{C}$ & $2,3^{\circ} \mathrm{C}$ \\
\hline Hora de la máxima & $9 \mathrm{~h}$ & $23 \mathrm{~h}$ & $1 \mathrm{~h}$ & $23 \mathrm{~h}$ \\
\hline Duración de la isla de calor & $24 \mathrm{~h}$ & $21 \mathrm{~h}$ & $15 \mathrm{~h}$ & $15 \mathrm{~h}$ \\
\hline Variables de la isla seca & $\begin{array}{c}\text { Diciembre } \\
\text { (verano) }\end{array}$ & $\begin{array}{c}\text { Enero } \\
\text { (verano) }\end{array}$ & $\begin{array}{c}\text { Junio } \\
\text { (invierno) }\end{array}$ & $\begin{array}{c}\text { Julio } \\
\text { (invierno) }\end{array}$ \\
\hline Intensidad media máxima & $-7,8 \%$ & $-8,8 \%$ & $6,4 \%$ & $-4,8 \%$ \\
\hline Hora de la máxima & $7 \mathrm{~h}$ & $5 \mathrm{~h}$ & $9 \mathrm{~h}$ & $7 \mathrm{~h}$ \\
\hline Duración de la isla seca & $10 \mathrm{~h}$ & $12 \mathrm{~h}$ & $10 \mathrm{~h}$ & $10 \mathrm{~h}$ \\
\hline
\end{tabular}

Tabla 2 - Intensidad media máxima, hora de la máxima y duración de la isla de calor y seca en Penápolis en diciembre (2014) y enero, junio y julio (2015).

Fuente: Elaborado por los autores.

La evolución media de la isla de calor y de la isla seca de los meses de diciembre (2014), enero, junio y julio (2015) en la ciudad de Penápolis muestra que las horas nocturnas son las de mayor actuación en la isla de calor (Figura 4). La isla seca también estuvo presente durante la noche y se presentó inexistente durante el día e inicio de la noche, sobre todo a partir de las $11 \mathrm{~h}$ hasta las $21 \mathrm{~h}$.

De este modo, se ha tornado evidente que el mes de enero presentó una isla de calor más intensa en comparación a diciembre, especialmente en los horarios nocturnos de las $19 \mathrm{~h}$ hasta las $5 \mathrm{~h}$. Durante este período, la isla de calor en diciembre ha oscilado entre $0,7^{\circ} \mathrm{C}$ a las $19 \mathrm{~h}$ y la máxima de $2,1^{\circ} \mathrm{C}$ a las $23 \mathrm{~h}$, mientras que en enero los valores oscilaron entre $1,3^{\circ} \mathrm{C}$ a las $19 \mathrm{~h}$ y $3,1^{\circ} \mathrm{C}$ a las $23 \mathrm{~h}$. Ya en relación a la isla seca, su aparición fuera más tarde, a las $23 \mathrm{~h}$, con una extensión hasta las primeras horas de la mañana pasando a estar ausente de las $9 \mathrm{~h}$, su intensidad fue mayor durante la madrugada con máximas de $-7,8 \%$ a las $7 \mathrm{~h}$ de diciembre y $-8,8 \%$ a las $5 \mathrm{~h}$ en enero. 

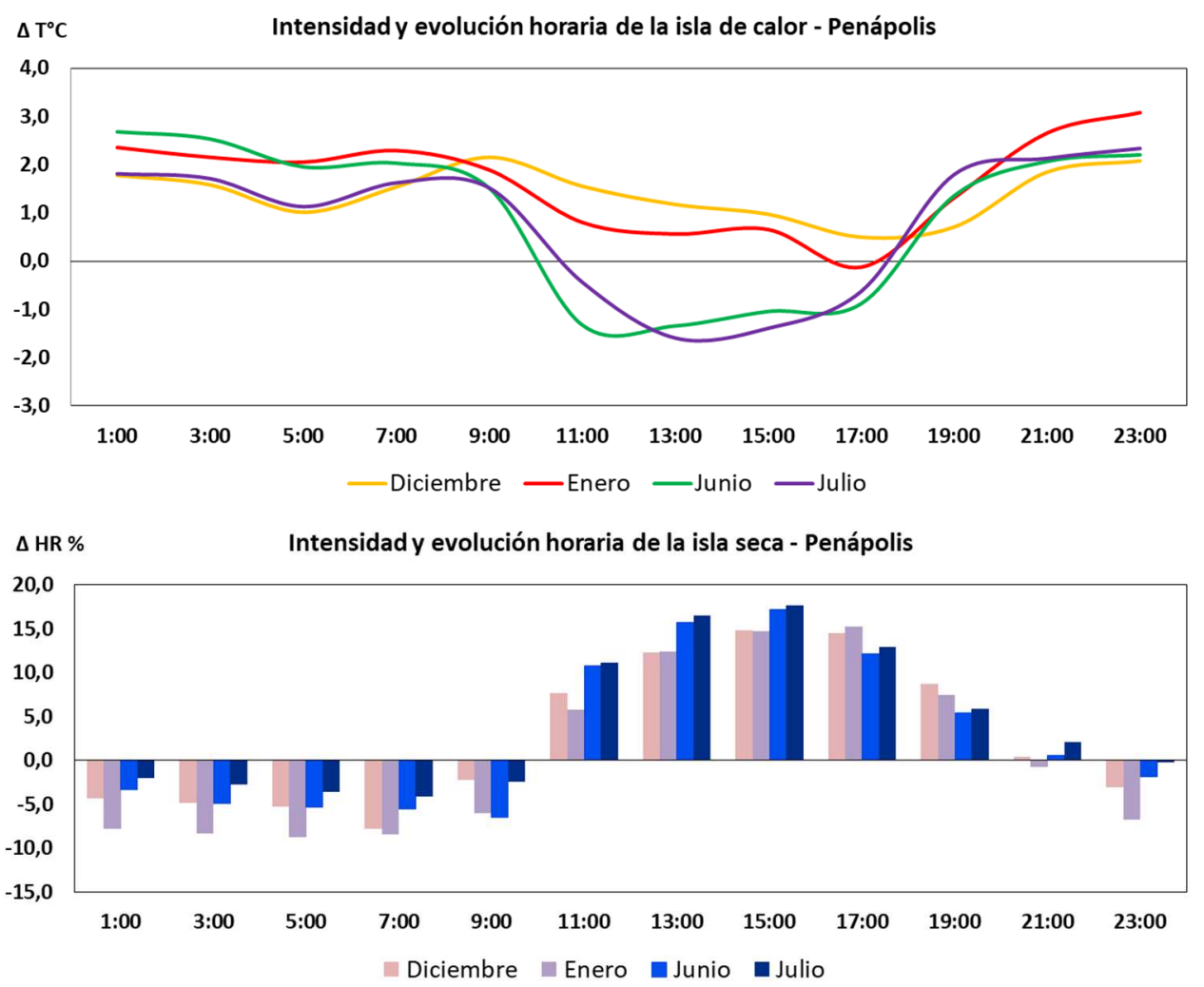

Figura 4 - Intensidad y evolución horaria de la isla de calor y seca en Penápolis en diciembre (2014) y enero, junio y julio (2015) - datos generales. Fuente: Elaborado por los autores.

Ya en junio y julio la isla de calor se presentó como un fenómeno exclusivamente nocturno con inicio a partir de las 19h, máxima durante la madrugada y en disminución hasta las 9h, cuando deja de existir. Luego, las máximas fueron registradas de seis a siete horas después de la puesta del sol, alcanzando en junio de $2,7^{\circ} \mathrm{C}$ a la $1 \mathrm{~h}$ y en julio $2,3^{\circ} \mathrm{C}$ a las $23 \mathrm{~h}$. En cuanto la isla seca surgió después del anochecer, en particular a las $23 \mathrm{~h}$ y se prolongó hasta las primeras horas de la mañana sobre todo hasta las 9h. La intensidad media máxima en junio fue de $-6,4 \%$ a las $9 h$ y en julio fue de $-4,1 \%$ a las $5 h$.

Así, a través de los valores medios calculados entre los dos meses representativos de cada estación, fue posible verificar que la isla de calor se difiere más entre las estaciones (Figura 5). En el verano tuvo una isla de calor permanente y con mayor magnitud, su intensidad disminuye por la tarde, principalmente a las $17 \mathrm{~h}$ y su máxima ocurrió por la noche a las $23 \mathrm{~h}$ con $2,6^{\circ} \mathrm{C}$. Ya en el invierno, la isla de calor deja de existir entre las $11 \mathrm{~h}$ y las $17 \mathrm{~h}$ y la máxima fue registrada fue de $2,3^{\circ} \mathrm{C}$ a las $23 \mathrm{~h}$. Ya la isla seca mostró un patrón similar entre las estaciones, que difieren sólo a la intensidad, la máxima en verano de intensidad media fue $8,1 \%$ y $-4,8 \%$ en el invierno, ambas registradas a las $7 \mathrm{~h}$. 


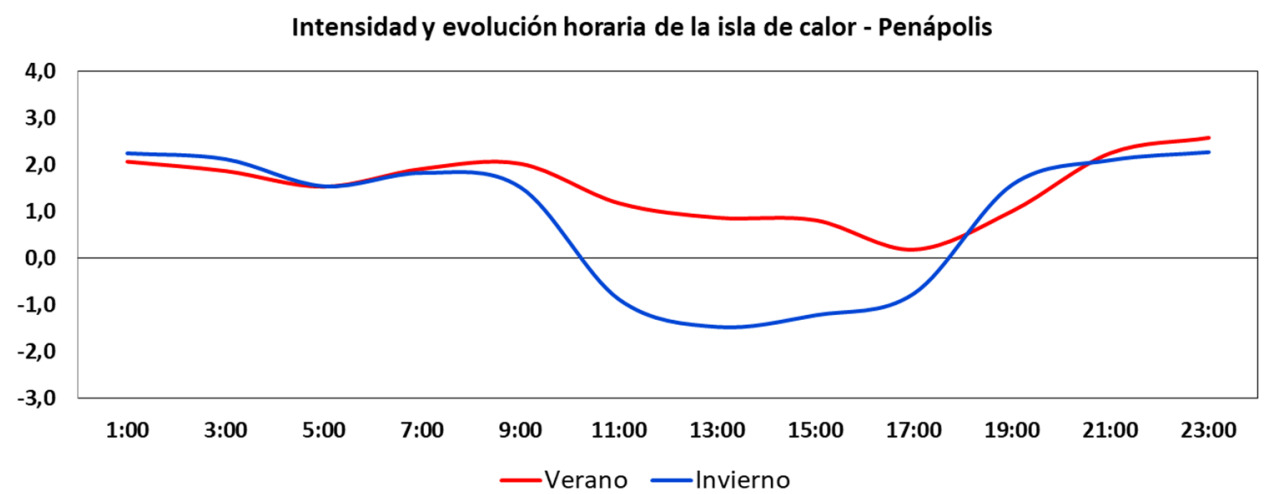

Intensidad y evolución horaria de la isla seca - Penápolis

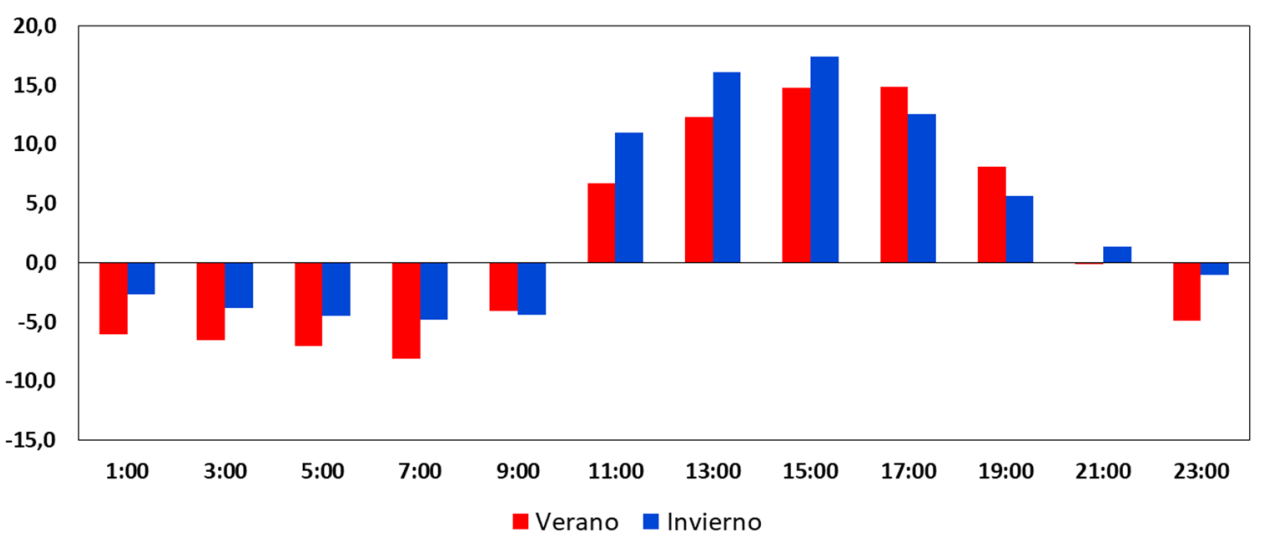

Figura 5 - Intensidad y evolución horaria de la isla de calor y seca en verano e invierno en Penápolis datos generales. Fuente: Elaborado por los autores.

\subsection{Intensidad y evolución horaria de la isla de calor e seca en días con lluvia}

En días con lluvia la intensidad media de la isla de calor en Penápolis se ha reducido, teniendo la máxima de $2,8^{\circ} \mathrm{C}$, registrada en enero a las $23 \mathrm{~h}$ (Tabla 3 ). Por lo tanto, algunas de las características siguen siendo similares a los datos generales, dado que la máxima continuó por la noche, principalmente a las $23 \mathrm{~h}$ y a la $1 \mathrm{~h}$. Además, diciembre siguió con una isla de calor permanente y enero permaneció con la intensidad media más alta entre los meses analizados. 


\begin{tabular}{c|c|c|c|c}
\hline Variables de la isla de calor & $\begin{array}{c}\text { Diciembre } \\
\text { (verano) }\end{array}$ & $\begin{array}{c}\text { Enero } \\
\text { (verano) }\end{array}$ & $\begin{array}{c}\text { Junio } \\
\text { (invierno) }\end{array}$ & $\begin{array}{c}\text { Julio } \\
\text { (invierno) }\end{array}$ \\
\hline Intensidad media máxima & $1,5^{\circ} \mathrm{C}$ & $2,8^{\circ} \mathrm{C}$ & $1,5^{\circ} \mathrm{C}$ & $0,4^{\circ} \mathrm{C}$ \\
\hline Hora de la máxima & $1 \mathrm{~h}$ & $23 \mathrm{~h}$ & $21 \mathrm{~h} \mathrm{e} 23 \mathrm{~h}$ & $1 \mathrm{~h}, 7 \mathrm{~h}, 19 \mathrm{~h}$ \\
\hline Duración de la isla de calor & $24 \mathrm{~h}$ & $21 \mathrm{~h}$ & $16 \mathrm{~h}$ & $9 \mathrm{~h}$ \\
\hline Variables de la isla seca & $\begin{array}{c}\text { Diciembre } \\
\text { (verano) }\end{array}$ & $\begin{array}{c}\text { Enero } \\
\text { (verano) }\end{array}$ & $\begin{array}{c}\text { Junio } \\
\text { (invierno) }\end{array}$ & $\begin{array}{c}\text { Julio } \\
\text { (invierno) }\end{array}$ \\
\hline Intensidad media máxima & $-4,4 \%$ & $-8,5 \%$ & - & - \\
\hline Hora de la máxima & $5 \mathrm{~h}$ & $5 \mathrm{~h} \mathrm{y} 7 \mathrm{~h}$ & - & - \\
\hline Duración de la isla de seca & $10 \mathrm{~h}$ & $10 \mathrm{~h}$ & - & - \\
\hline
\end{tabular}

Tabla 3 - Intensidad media máxima, hora de la máxima y duración de la isla de calor y seca en Penápolis con lluvia en diciembre (2014) y enero, junio y julio (2015).

Fuente: Elaborado por los autores.

A través de la Figura 6 se puede observar que la isla de calor en días con lluvia ha oscilado entre $0,3^{\circ} \mathrm{C}$ y $2,8^{\circ} \mathrm{C}$, y los valores más altos se registraron en la noche entre las $21 \mathrm{~h}$ y las $3 \mathrm{~h}$. Con respecto a las diferencias mensuales en el verano, diciembre tuvo una isla de menor intensidad y duración más larga, con un máximo de $1,5^{\circ} \mathrm{C}$ con $24 \mathrm{~h}$ de duración. Ya en enero fue registrada la mayor intensidad $\operatorname{con} 2,8^{\circ} \mathrm{C}$, pero hubo una disminución en la duración de la isla de calor para $21 \mathrm{~h}$. Vale destacar que, aunque algunos horarios no presentaron isla de calor, durante estos días no hubo registrados valores negativos, es decir, no hubo isla de frescor en la ciudad. La isla seca señaló un patrón similar entre los meses, siendo que la intensidad máxima de la isla seca fue de $-4,4 \%$ en diciembre y $-8,5 \%$ en enero, ambos registrados a las $5 \mathrm{~h}$ (Tabla 3$)$.

En junio y julio de 2015 en días con lluvia la isla de calor tuvo intensidad más reducida, llegando a un máximo de $1,5^{\circ} \mathrm{C}$ en junio, a las $21 \mathrm{~h}$ y a las $23 \mathrm{~h}$, y $0,4^{\circ} \mathrm{C}$ en julio a la $1 \mathrm{~h}$, a las $7 \mathrm{~h}$ y a las $23 \mathrm{~h}$. Los valores negativos fueron registrados por la mañana y por la tarde, entre las $7 \mathrm{~h}$ y las $13 \mathrm{~h}$ en junio y entre las $11 \mathrm{~h}$ y las $17 \mathrm{~h}$ en julio, lo que demuestra la ausencia de una isla de calor durante el día en ambos meses. La isla seca fue inexistente en días con lluvia en los meses de invierno, es decir, la ciudad fue más húmeda que el rural en todos los horarios. Lo que difiere entre estos meses fuera la magnitud del fenómeno, ya que junio tuvo una isla de calor más intensa mientras que julio mostró una isla húmeda más pronunciada. 

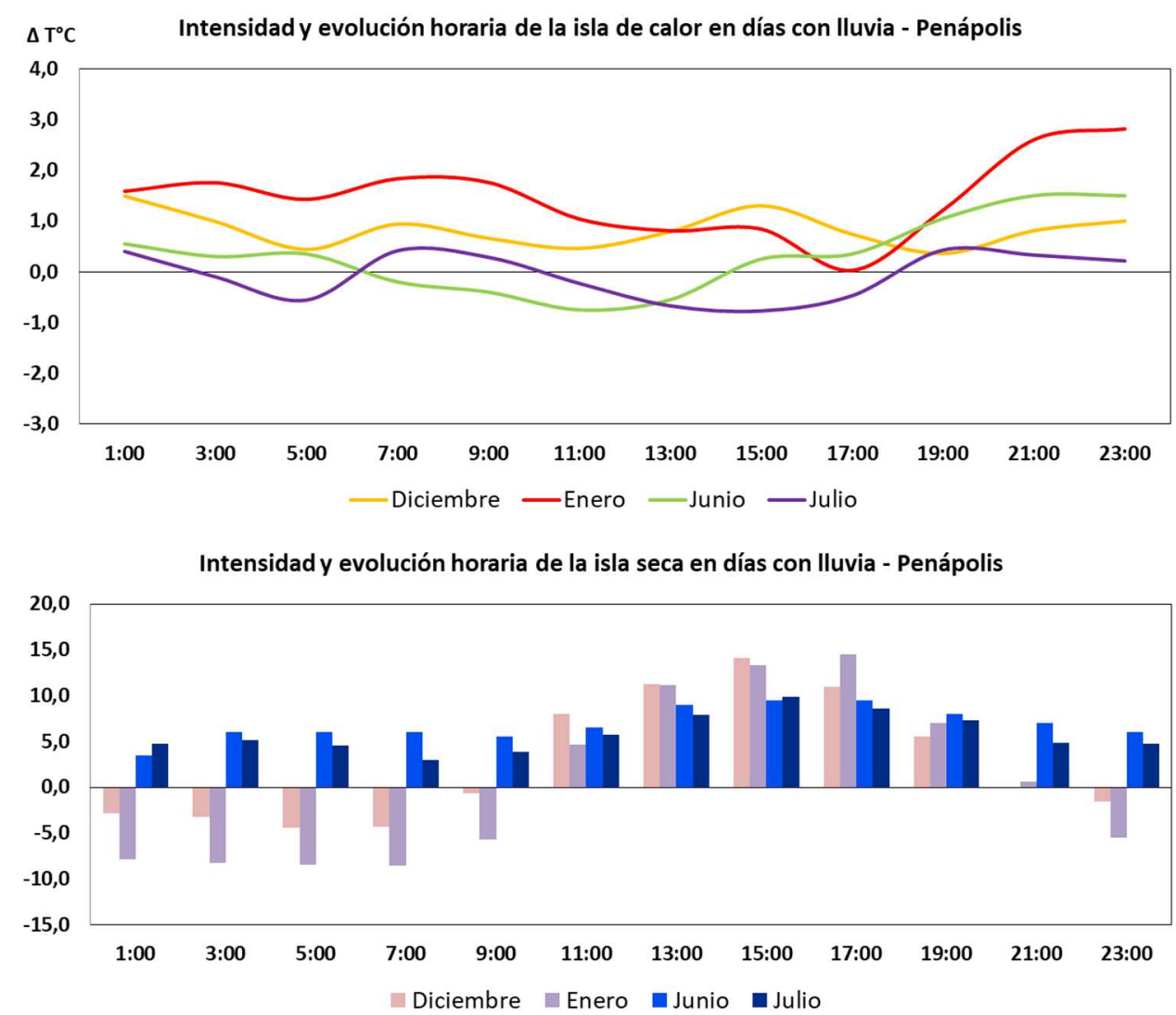

Figura 6- Intensidad y evolución horaria de la isla de calor y seca en días con lluvia - Penápolis en diciembre (2014) y enero, junio y julio (2015). Fuente: Elaborado por los autores.

De este modo, en estos días la isla de calor también fue más intensa en el verano, con máxima de $1,9^{\circ} \mathrm{C}$ en verano y en el invierno $0,9^{\circ} \mathrm{C}$ (Figura 7). Hubo un aumento en la intensidad media después de las $19 \mathrm{~h}$, con fuerza máxima a las $23 \mathrm{~h}$. La isla seca se mostró muy diferente entre las estaciones. En el verano hubo una isla seca entre las $23 \mathrm{~h}$ y las $9 \mathrm{~h}$, con intensidad máxima de $-6,4 \%$ a las $7 \mathrm{~h}$ y una isla húmeda entre las $11 \mathrm{~h}$ y $21 \mathrm{~h}$, con intensidad máxima de $13,7 \%$ a las $15 \mathrm{~h}$. En el invierno no hubo presencia de islas secas, solamente una isla húmeda que ha estado presente durante todo el día, con mayor intensidad a las $15 \mathrm{~h}$ cuando alcanzó el 9,7\%. 

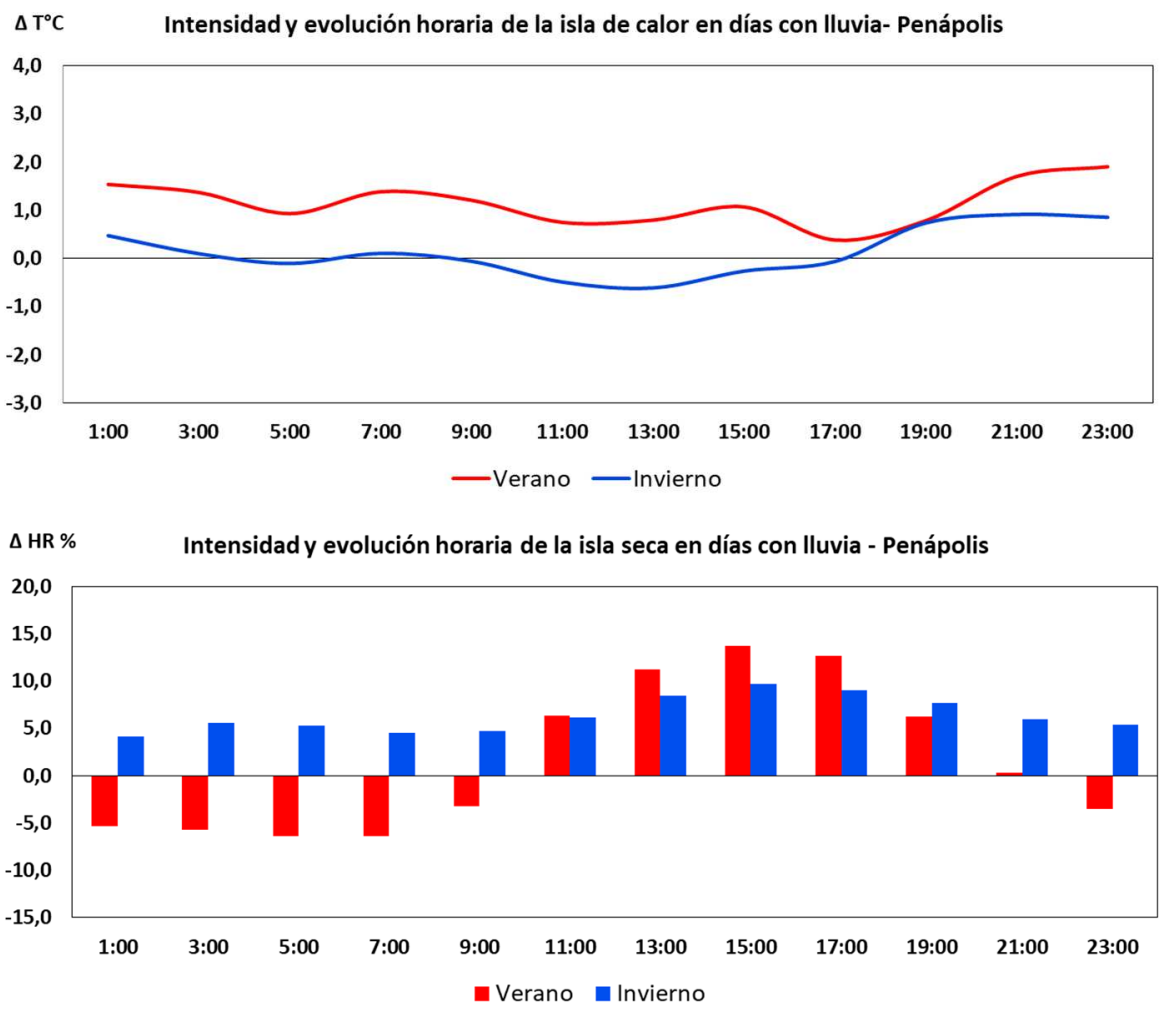

Figura 7 - Intensidad y evolución horaria de la isla de calor y seca en verano e invierno en días con lluvia - Penápolis. Fuente: Elaborado por los autores.

\subsection{Intensidad y evolución horaria de la isla de calor e seca en días sin lluvia}

Durante los días sin lluvia se observó el aumento de la intensidad media de la isla de calor con máximas de $2,9^{\circ} \mathrm{C}$ en diciembre, $3,3^{\circ} \mathrm{C}$ en enero, $2,8^{\circ} \mathrm{C}$ en junio y $3^{\circ} \mathrm{C}$ en julio (Tabla 4 ). La más grande duración fue en el verano con $24 \mathrm{~h}$ y $21 \mathrm{~h}$. Las horas de máxima continuaron durante la noche, sobre todo a las $23 \mathrm{~h}$ y a la $1 \mathrm{~h}$, y diciembre siguió con la mayor intensidad por la mañana a las $9 \mathrm{~h}$.

\begin{tabular}{c|c|c|c|c}
\hline Variables de la isla de calor & $\begin{array}{c}\text { Diciembre } \\
\text { (verano) }\end{array}$ & $\begin{array}{c}\text { Enero } \\
\text { (verano) }\end{array}$ & $\begin{array}{c}\text { Junio } \\
\text { (invierno) }\end{array}$ & $\begin{array}{c}\text { Julio } \\
\text { (invierno) }\end{array}$ \\
\hline Intensidad media máxima & $2,9^{\circ} \mathrm{C}$ & $3,3^{\circ} \mathrm{C}$ & $2,8^{\circ} \mathrm{C}$ & $3^{\circ} \mathrm{C}$ \\
\hline Hora de la máxima & $9 \mathrm{~h}$ & $23 \mathrm{~h}$ & $1 \mathrm{~h}$ & $1 \mathrm{~h}$ \\
\hline Duración de la isla de calor & $24 \mathrm{~h}$ & $21 \mathrm{~h}$ & $16 \mathrm{~h}$ & $16 \mathrm{~h}$ \\
\hline Variables de la isla seca & $\begin{array}{c}\text { Diciembre } \\
\text { (verano) }\end{array}$ & $\begin{array}{c}\text { Enero } \\
\text { (verano) }\end{array}$ & $\begin{array}{c}\text { Junio } \\
\text { (invierno) }\end{array}$ & $\begin{array}{c}\text { Julio } \\
\text { (invierno) }\end{array}$ \\
\hline Intensidad media máxima & $-9,4 \%$ & $-8,3 \%$ & $-6,2 \%$ & $-6,3 \%$ \\
\hline Hora de la máxima & $7 \mathrm{~h}$ & $7 \mathrm{~h}$ & $7 \mathrm{~h}$ & $7 \mathrm{~h}$ \\
\hline Duración de la isla seca & $10 \mathrm{~h}$ & $11 \mathrm{~h}$ & $10 \mathrm{~h}$ & $10 \mathrm{~h}$ \\
\hline
\end{tabular}

Tabla 4 - Intensidad media máxima, hora de la máxima y duración de la isla de calor y seca en Penápolis sin lluvia en diciembre (2014) y enero, junio y julio (2015).

Fuente: Elaborado por los autores. 
En días sin lluvia se puede notar un patrón de intensidad mayor en la noche con inicio, principalmente a las $21 \mathrm{~h}$ y finalización a las $9 \mathrm{~h}$ (Figura 8). La mayor intensidad de la isla de calor fue en enero con $3,3^{\circ} \mathrm{C}$ registrada a las $23 \mathrm{~h}$. Junio y julio mostraron intensidad y un patrón similar, con calentamiento durante la noche e isla de frescor de las $11 \mathrm{~h}$ hasta las $17 \mathrm{~h}$. La isla seca ocurrió por la noche y en las primeras horas de la mañana, a partir de las $23 \mathrm{~h}$ hasta las 9h, ya la isla húmeda apareció por la tarde e inicio de la noche, de las $11 \mathrm{~h}$ hasta las 19h. Sin embargo, hubo un aumento en la intensidad de la isla seca, que alcanzó el valor más alto en diciembre a las $7 \mathrm{~h}$ con $-9,4 \%$.

En los meses de diciembre y enero la isla de calor se presentó como un fenómeno nocturno, que pierde intensidad o deja de existir por la tarde. Sin embargo, diciembre tuvo su mayor intensidad por la mañana a las $9 \mathrm{~h}$, mientras que en enero la intensidad máxima de la isla de calor fue a las $23 \mathrm{~h}$. Durante estos meses en días sin lluvia, casi no hubo presencia de islas frescas excepto a las $17 \mathrm{~h}$ en enero. La isla seca mostró intensidad máxima media de $-9,4 \%$ en diciembre y $-8,3 \%$ en enero, ambas señaladas a las $7 \mathrm{~h}$ (Tabla 4).
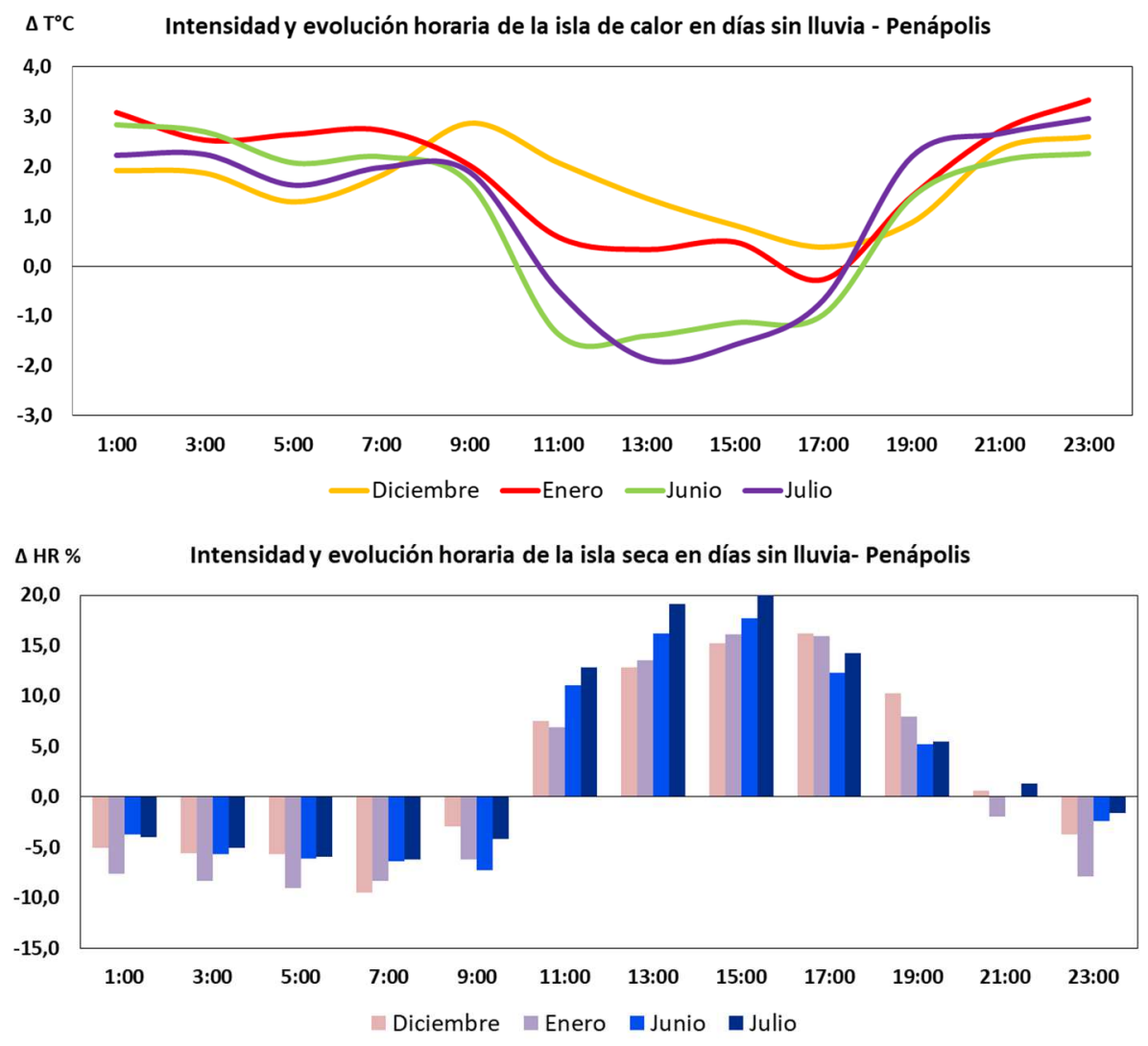

Figura 8 - Intensidad y evolución horaria de la isla de calor y seca en días sin lluvia - Penápolis en diciembre (2014) y enero, junio y julio (2015). Fuente: Elaborado por los autores. 
En junio y julio la isla de calor también tuvo mayor intensidad en los horarios nocturnos, con inicio a las $21 \mathrm{~h}$ y finalización a las $9 \mathrm{~h}$, la máxima fuera de $2,8^{\circ} \mathrm{C}$ a la $1 \mathrm{~h}$ y $3^{\circ} \mathrm{C}$ a las $23 \mathrm{~h}$, respectivamente. En los dos meses las islas de frescor fueron encontradas en el final de la mañana y por la tarde, entre las $11 \mathrm{~h}$ y las $17 \mathrm{~h}$, las intensidades variaron entre $-1,0^{\circ} \mathrm{C}$ y $-1,4^{\circ} \mathrm{C}$ en junio y $-0,5^{\circ} \mathrm{C}$ y $-1,9^{\circ} \mathrm{C}$ en julio, y las máximas se registraron a las $13 \mathrm{~h}$. El patrón de islas secas y húmedas se mantuvieron, ya que en junio y julio tuvieron una isla seca de las $23 \mathrm{~h}$ hasta las $9 \mathrm{~h}$ de la mañana, con la intensidad máxima de $-6.4 \%$ a las $7 \mathrm{~h}$ y una isla húmeda de las $11 \mathrm{~h}$ hasta las $19 \mathrm{~h}$, con intensidad máxima de $20 \%$ a las $15 \mathrm{~h}$.

Con respecto a las variaciones estacionales en los días sin lluvia, durante el verano se tuvo una isla de calor constante, que casi desapareció por la tarde, especialmente a las $17 \mathrm{~h}$ (Figura 9). Por el contrario, en el invierno la isla de calor dejó de existir por un período más largo, durante toda la tarde desde las $11 \mathrm{~h}$ hasta las $17 \mathrm{~h}$. Los horarios nocturnos se mantuvieron como los de mayor intensidad de la isla de calor urbana, en especial a las $23 \mathrm{~h}$, horario de máxima intensidad en ambas estaciones con $3^{\circ} \mathrm{C}$ en verano y $2,6^{\circ} \mathrm{C}$ en invierno. En ambas estaciones la isla húmeda ocurrió por la tarde y la isla secas por la noche, madrugada e inicio de la mañana.
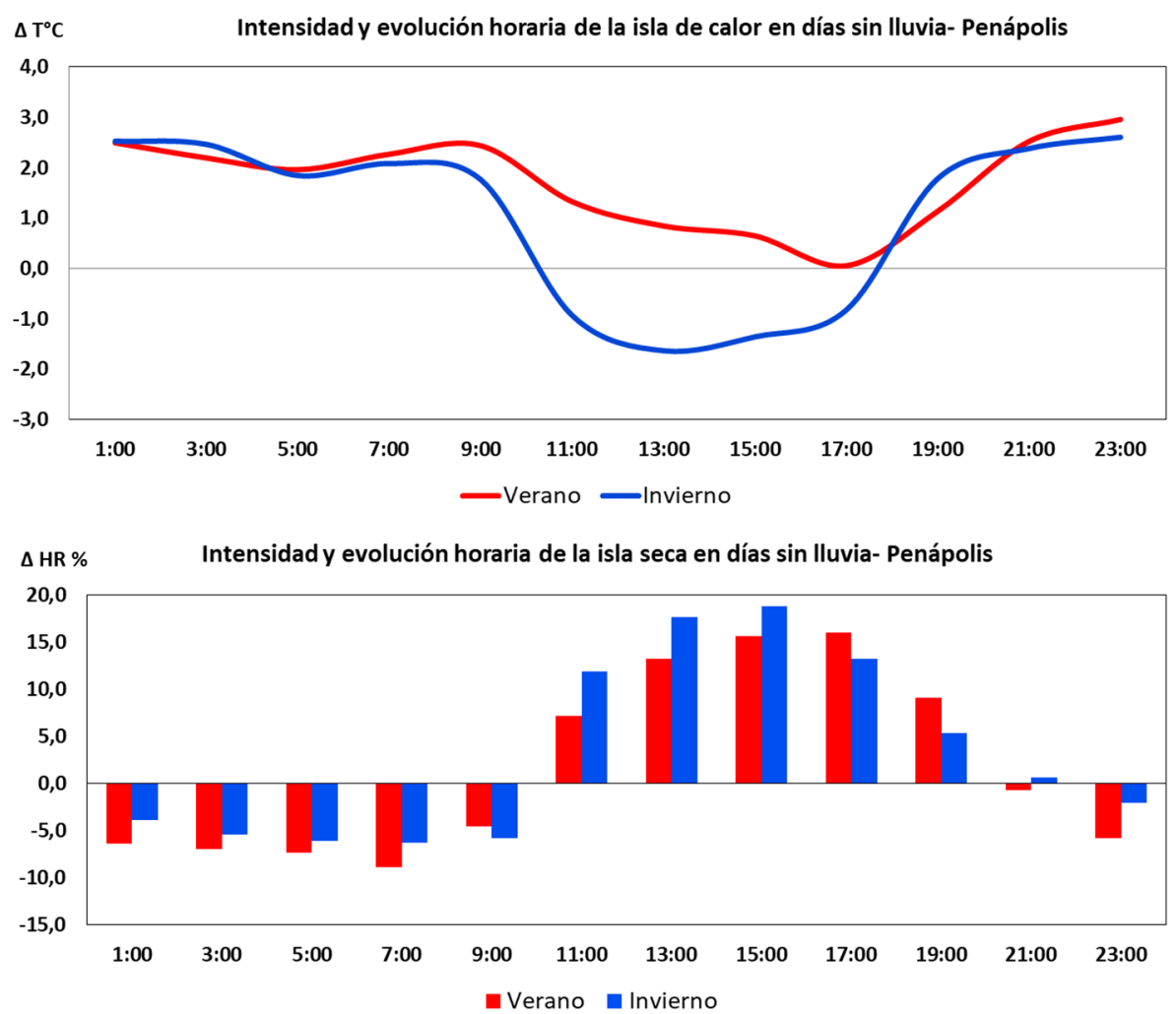

Figura 9 - Intensidad y evolución horaria de la isla de calor y seca en verano e invierno en días sin Iluvia - Penápolis. Fuente: Elaborado por los autores 


\subsection{Intensidad y evolución horaria de la isla de calor e seca en días con viento}

La isla de calor en condiciones con viento alcanzó $2,2^{\circ} \mathrm{C}$ en diciembre, $3,3^{\circ} \mathrm{C}$ en enero, $2,3^{\circ} \mathrm{C}$ en junio y $2^{\circ} \mathrm{C}$ en julio (Tabla 5). Diciembre continuó con la mayor duración de 24 horas, seguido de enero con $21 \mathrm{~h}$ y junio y julio con $16 \mathrm{~h}$. Los picos más altos de intensidad se mantuvieron por la noche, especialmente a las $23 \mathrm{~h}$ en enero, a las $1 \mathrm{~h}$ en junio y a las $21 \mathrm{~h}$ en julio. El distinto patrón de diciembre ha persistido, con la mayor intensidad por la mañana a las $9 \mathrm{~h}$.

\begin{tabular}{c|c|c|c|c}
\hline Variables de la isla de calor & $\begin{array}{c}\text { Diciembre } \\
\text { (verano) }\end{array}$ & $\begin{array}{c}\text { Enero } \\
\text { (verano) }\end{array}$ & $\begin{array}{c}\text { Junio } \\
\text { (invierno) }\end{array}$ & $\begin{array}{c}\text { Julio } \\
\text { (invierno) }\end{array}$ \\
\hline Intensidad media máxima & $2,2^{\circ} \mathrm{C}$ & $3,3^{\circ} \mathrm{C}$ & $2,3^{\circ} \mathrm{C}$ & $2{ }^{\circ} \mathrm{C}$ \\
\hline Hora de la máxima & $9 \mathrm{~h}$ & $23 \mathrm{~h}$ & $1 \mathrm{~h}$ & $21 \mathrm{~h}$ \\
\hline Duración de la isla de calor & $24 \mathrm{~h}$ & $21 \mathrm{~h}$ & $16 \mathrm{~h}$ & $16 \mathrm{~h}$ \\
\hline Variables de la isla seca & $\begin{array}{c}\text { Diciembre } \\
\text { (verano) }\end{array}$ & $\begin{array}{c}\text { Enero } \\
\text { (verano) }\end{array}$ & $\begin{array}{c}\text { Junio } \\
\text { (invierno) }\end{array}$ & $\begin{array}{c}\text { Julio } \\
\text { (invierno) }\end{array}$ \\
\hline Intensidad media máxima & $-8,6 \%$ & $-8,8 \%$ & $-5,2 \%$ & $-4,1 \%$ \\
\hline Hora de la máxima & $7 \mathrm{~h}$ & $3 \mathrm{~h}$ & $7 \mathrm{~h}$ & $7 \mathrm{~h}$ \\
\hline Duración de la isla seca & $10 \mathrm{~h}$ & $12 \mathrm{~h}$ & $10 \mathrm{~h}$ & $10 \mathrm{~h}$ \\
\hline
\end{tabular}

Tabla 5 - Intensidad media máxima, hora de la máxima y duración de la isla de calor y seca en Penápolis con viento en diciembre (2014) y enero, junio y julio (2015).

Fuente: Elaborado por los autores.

En días con viento también ha observado que enero se mantuvo la mayor intensidad de la isla de calor y diciembre continuó con una isla de calor constante. Junio y julio siguieron presentando intensidad y patrón similar, con calentamiento durante la noche, con intensidades medias máximas de $2,3^{\circ} \mathrm{C}$ y $2^{\circ} \mathrm{C}$, respectivamente, y la isla de frescor de las $11 \mathrm{~h}$ hasta las $17 \mathrm{~h}$, con intensidades medias máximas de $-1,3^{\circ} \mathrm{C}$ en junio y $-1,7^{\circ} \mathrm{C}$ en julio (Figura 10). La isla seca también estuvo presente en el período nocturno y en las primeras horas de la mañana, su máxima ocurrió en condiciones de verano en enero con el 8,8\% a las $3 \mathrm{~h}$ (Tabla $5)$.

Al respecto de las diferencias entre los meses de diciembre y enero se observó que enero ha mostrado una isla de calor más pronunciada, con una intensidad media máxima de $3,3^{\circ} \mathrm{C}$ a las $23 \mathrm{~h}$. Ya la isla de frescor se expresó durante el período de la tarde a las $17 \mathrm{~h}$. Diciembre presentó una isla de calor con menor intensidad con máxima media de $2,2^{\circ} \mathrm{C}$, con pico de mayor fuerza por la mañana a las 9h pero con duración constante. La isla seca presentó 
inicio a las $23 \mathrm{~h}$ y finalización a las $9 \mathrm{~h}$, sus máximas alcanzaron $-8,6 \%$ en diciembre a las $7 \mathrm{~h}$ y$8,8 \%$ en enero a las $3 \mathrm{~h}$. Ya la isla húmeda estuvo presente por la tarde e inicio de la noche y alcanzó las intensidades máximas de $15,0 \%$ en diciembre a las $15 \mathrm{~h}$ y $15,7 \%$ en enero a las $17 \mathrm{~h}$.

Los meses de junio y julio de 2015 fueron similares en cuanto a la intensidad de la isla de calor, junio presentó la máxima de $2,3^{\circ} \mathrm{C}$ a la $1 \mathrm{~h}$ y julio de $2^{\circ} \mathrm{C}$ a las $21 \mathrm{~h}$. Por lo tanto, en tales condiciones climáticas, la mayor intensidad de la isla de calor fue adelantada en julio en comparación a junio. Durante estos meses se verificó también, una mayor extensión de la isla de frescor, que actuó durante el período vespertino, en particular entre las $11 \mathrm{~h}$ y las $17 \mathrm{~h}$.

En junio e julio la isla seca comenzó por la tarde, tuvo su mayor intensidad en las primeras horas de la mañana y dejó de existir después de las 9h, sólo diferenciándose en intensidad con máximas de $-5,2 \%$ en junio y $-4,1 \%$ en julio. Luego, la isla húmeda tuvo su desarrollo a partir de las $11 \mathrm{~h}$, perpetuándose durante toda la tarde hasta las $21 \mathrm{~h}$, sus intensidades medias máximas fueron de $15,1 \%$ en junio y $17,6 \%$ en julio, ambas registradas a las $13 \mathrm{~h}$.
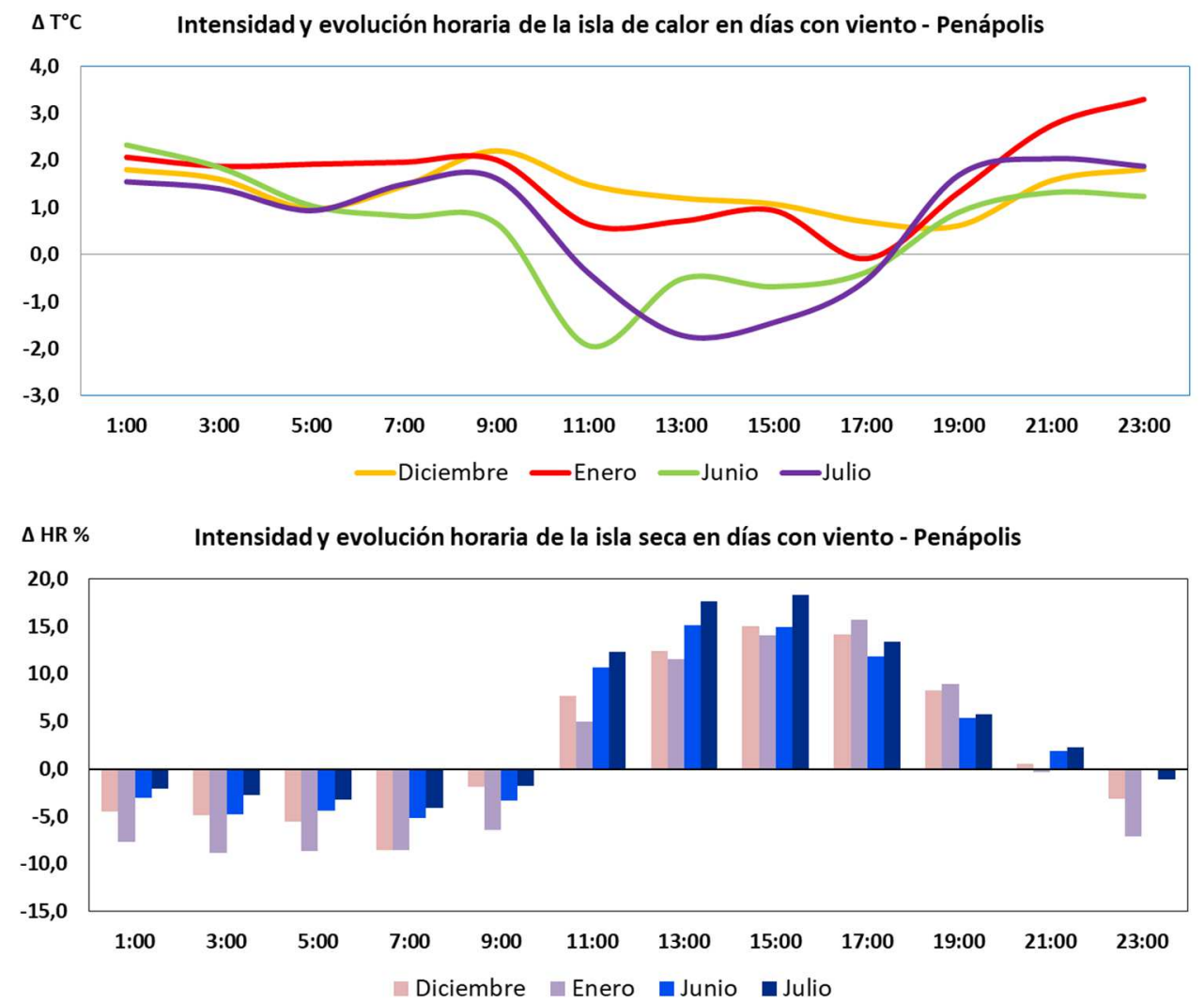

Figura 10 - Intensidad y evolución horaria de la isla de calor y seca en días con viento - Penápolis en diciembre (2014) y enero, junio y julio (2015). Fuente: Elaborado por los autores 
Por lo tanto, la isla de calor del verano se presentó permanente y con mayor intensidad, su magnitud disminuyó por la tarde, en especial a las $17 \mathrm{~h}$ y su máxima intensidad se registró en periodo nocturno, a las $23 \mathrm{~h}$ con $2,6^{\circ} \mathrm{C}$ (Figura 11). Mientras que, en el invierno, la isla de calor se ha configurado como un fenómeno de menor intensidad y duración, con un máximo de $1,9^{\circ} \mathrm{C}$ a la $1 \mathrm{~h}$ y 15 horas de duración, con inicio las $23 \mathrm{~h}$ y finalización a las $9 \mathrm{~h}$. En ambas estaciones la isla seca fue un fenómeno nocturno que se extendió por la madrugada y por la mañana. Ya la isla húmeda se presentó por la tarde y por la noche, específicamente entre las $11 \mathrm{~h}$ y las $21 \mathrm{~h}$. Lo que se puede distinguir es la intensidad y los horarios de las máximas encontradas, la isla seca en el verano alcanzó $-8,6 \%$ y en el invierno $-4,6 \%$, ambas registradas a las $7 \mathrm{~h}$.
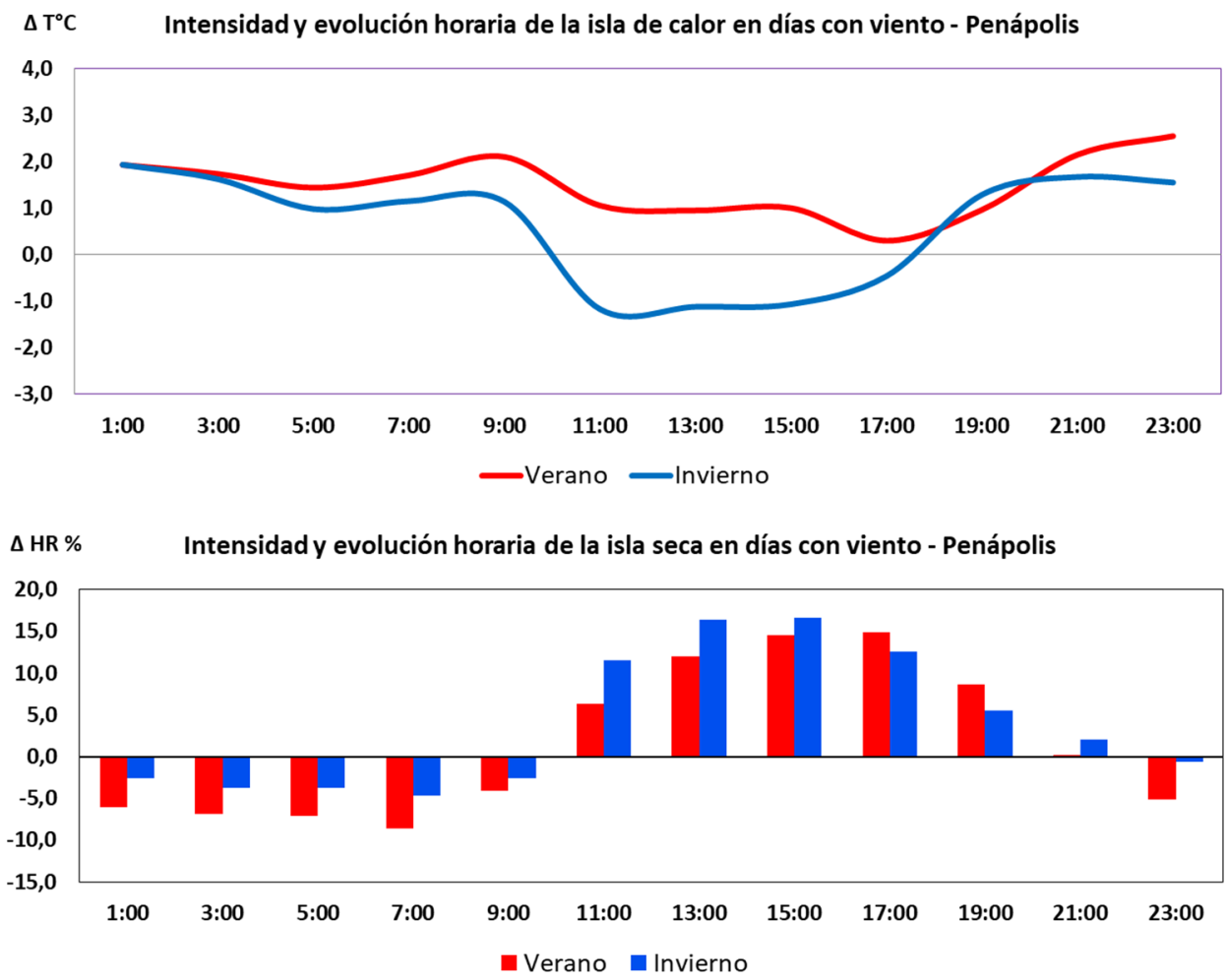

Figura 11 - Intensidad y evolución horaria de la isla de calor y seca en verano e invierno en días con viento - Penápolis. Fuente: Elaborado por los autores

\subsection{Intensidad y evolución horaria de la isla de calor e seca en días sin viento}

Bajo tales condiciones climáticas, la isla de calor en Penápolis presentó las mayores magnitudes en comparación con los análisis ya desarrollados, alcanzando la máxima de $3,5^{\circ} \mathrm{C}$ a las $23 \mathrm{~h}$ en diciembre (Tabla 6 ). Algunas características se mantuvieron semejantes, 
por ejemplo, los horarios de máxima intensidad, que continuaron ocurriendo por la noche y la madrugada.

\begin{tabular}{c|c|c|c|c}
\hline Variables de la isla de calor & $\begin{array}{c}\text { Diciembre } \\
\text { (verano) }\end{array}$ & $\begin{array}{c}\text { Enero } \\
\text { (verano) }\end{array}$ & $\begin{array}{c}\text { Junio } \\
\text { (invierno) }\end{array}$ & $\begin{array}{c}\text { Julio } \\
\text { (invierno) }\end{array}$ \\
\hline Intensidad media máxima & $3,5^{\circ} \mathrm{C}$ & $3,0^{\circ} \mathrm{C}$ & $2,9^{\circ} \mathrm{C}$ & $2,9^{\circ} \mathrm{C}$ \\
\hline Hora de la máxima & $23 \mathrm{~h}$ & $1 \mathrm{~h} \mathrm{e} \mathrm{h}$ & $1 \mathrm{~h} \mathrm{e} 3 \mathrm{~h}$ & $23 \mathrm{~h}$ \\
\hline Duración de la isla de calor & $21 \mathrm{~h}$ & $21 \mathrm{~h}$ & $16 \mathrm{~h}$ & $16 \mathrm{~h}$ \\
\hline Variables de la isla seca & $\begin{array}{c}\text { Diciembre } \\
\text { (verano) }\end{array}$ & $\begin{array}{c}\text { Enero } \\
\text { (verano) }\end{array}$ & $\begin{array}{c}\text { Junio } \\
\text { (invierno) }\end{array}$ & $\begin{array}{c}\text { Julio } \\
\text { (invierno) }\end{array}$ \\
\hline Intensidad media máxima & $-4,6 \%$ & $-9,0 \%$ & $-4,1 \%$ & $-5,7 \%$ \\
\hline Hora de la máxima & $3 \mathrm{~h}$ & $5 \mathrm{~h}$ & $7 \mathrm{~h}$ & $9 \mathrm{~h}$ \\
\hline Duración de la isla seca & $12 \mathrm{~h}$ & $12 \mathrm{~h}$ & $8 \mathrm{~h}$ & $10 \mathrm{~h}$ \\
\hline
\end{tabular}

Tabla 6 - Intensidad media máxima, hora de la máxima y duración da isla de calor urbana en Penápolis sin viento en diciembre (2014) y enero, junio y julio (2015).

Fuente: Elaborado por los autores.

A través de la intensidad y la evolución horaria de la isla de calor en días sin viento (Figura 12) fue posible observar que en todos los meses analizados a las $17 \mathrm{~h}$, se tuvo una disminución de las diferencias térmicas positivas, configurando así la presencia de una isla de frescor en la ciudad. Además, también se verificó un patrón muy similar entre los meses, con mayores intensidades entre las $19 \mathrm{~h}$ y las $9 \mathrm{~h}$. Las máximas fueron de $3,5^{\circ} \mathrm{C}$ a las $23 \mathrm{~h}$ en diciembre, y $3^{\circ} \mathrm{C}$ a la $1 \mathrm{~h}$ y las $7 \mathrm{~h}$ en enero, $2,9^{\circ} \mathrm{C}$ a la $1 \mathrm{~h}$ y a las $3 \mathrm{~h}$ en junio y $2,9^{\circ} \mathrm{C}$ a las $23 \mathrm{~h}$ en julio. Al mismo tiempo, en este período del día también estuvo presente la isla seca, la cual actuó entre las $21 \mathrm{~h}$ hasta las $9 \mathrm{~h}$. Su intensidad máxima ocurrió en enero a las $9 \mathrm{~h}$, cuando alcanzó -9,0\% (Tabla 6). 

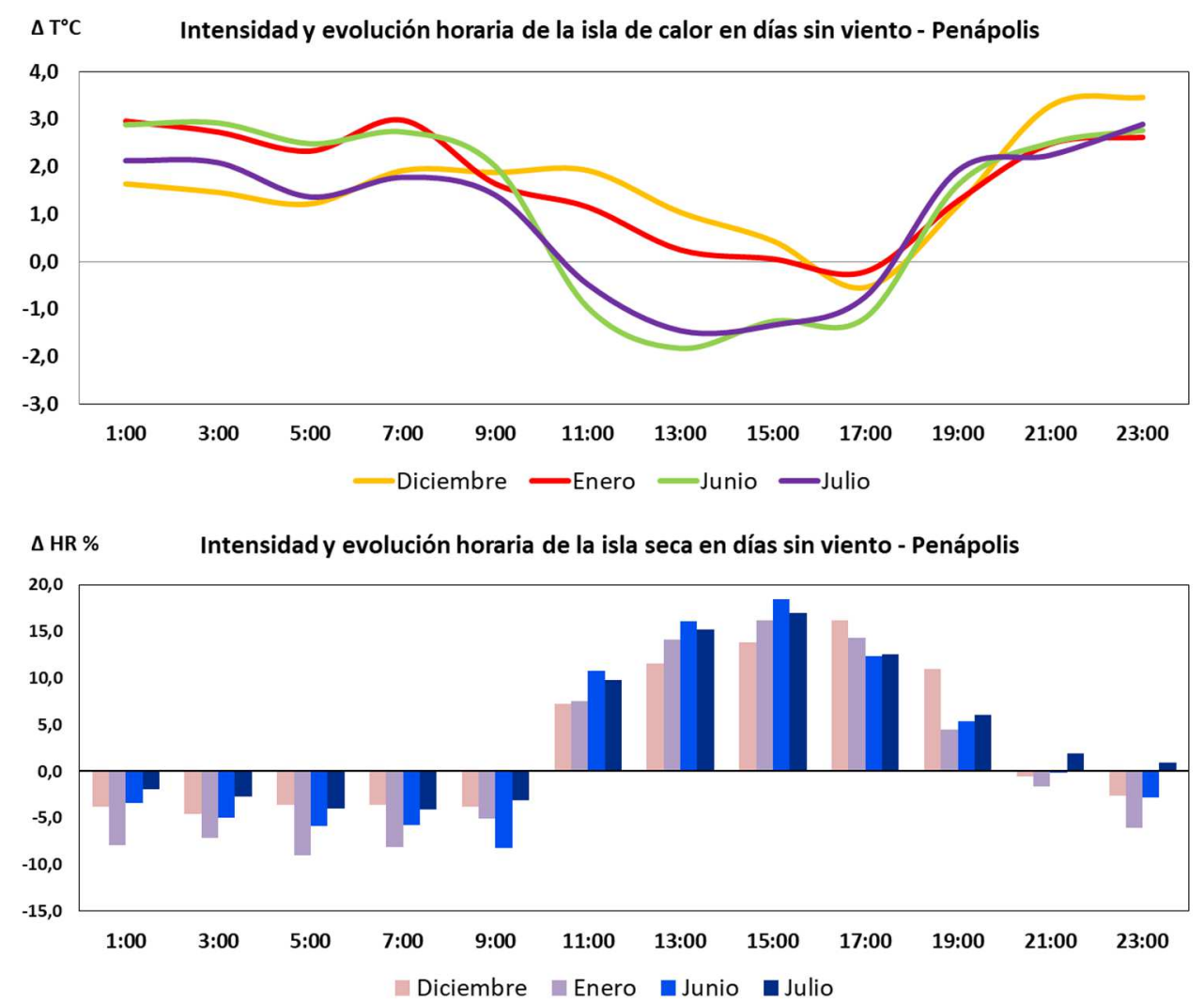

Figura 12 - Intensidad y evolución horaria de la isla de calor e seca en días sin viento - Penápolis en diciembre (2014) y enero, junio y julio (2015). Fuente: Elaborado por los autores.

Diciembre y enero presentaron muchas semejanzas con la actuación de isla de calor a partir de las $19 \mathrm{~h}$ hasta las $11 \mathrm{~h}$, las máximas fueron de $3,5^{\circ} \mathrm{C}$ en diciembre y de $3^{\circ} \mathrm{C}$ en enero. Además, hubo presencia de una isla de frescor de baja magnitud registrada a las $17 \mathrm{~h}$, con intensidades de $-0,5^{\circ} \mathrm{C}$ en diciembre y $-0,2^{\circ} \mathrm{C}$ en enero. Lo que difiere entre los meses, principalmente son los horarios de máximas, ya que en diciembre las intensidades más altas se registraron a las $21 \mathrm{~h}$ y a las $23 \mathrm{~h}$ y en enero a la $1 \mathrm{~h}$ y a las $7 \mathrm{~h}$ de la mañana. En los dos meses la isla seca estuvo presente entre las $21 \mathrm{~h}$ y las $9 \mathrm{~h}$ y la isla húmeda ocurrió entre las $11 \mathrm{~h}$ y las $19 \mathrm{~h}$. La isla seca registró el máximo de $-4,6 \%$ a las $3 \mathrm{~h}$ de diciembre y $-9 \%$ a las $5 \mathrm{~h}$ en enero (Tabla 6), ya la isla húmeda presentó intensidad de $16,2 \%$ a las $17 \mathrm{~h}$ en diciembre y a las $15 \mathrm{~h}$ en enero.

En junio y julio en días sin viento la isla de calor actúo entre las $19 \mathrm{~h}$ y las $9 \mathrm{~h}$, su intensidad máxima alcanzó $2,9^{\circ} \mathrm{C}$ en ambos meses y fue registrado a la $1 \mathrm{~h}$ y a las $3 \mathrm{~h}$ en junio y a las $23 \mathrm{~h}$ en julio. Al final de la mañana y durante toda la tarde, entre las $11 \mathrm{~h}$ y $17 \mathrm{~h}$ se tuvo la presencia de la isla de frescor, cuya intensidad máxima fue de $-1,8^{\circ} \mathrm{C}$ en junio $\mathrm{y}-1,5^{\circ} \mathrm{C}$ en julio, ambas registradas a las $17 \mathrm{~h}$. En relación a la isla húmeda Julio presentó mayor 
duración con inicio a las $11 \mathrm{~h}$ de la mañana y terminó a las $23 \mathrm{~h}$, mientras que en junio la isla húmeda dejó de existir a las $19 \mathrm{~h}$.

Por lo tanto, hubo diferencias significativas entre las estaciones analizadas. La isla de calor fuera de mayor duración e intensidad en el verano, la cual actúo desde las 19h hasta las 15h (Figura 13).
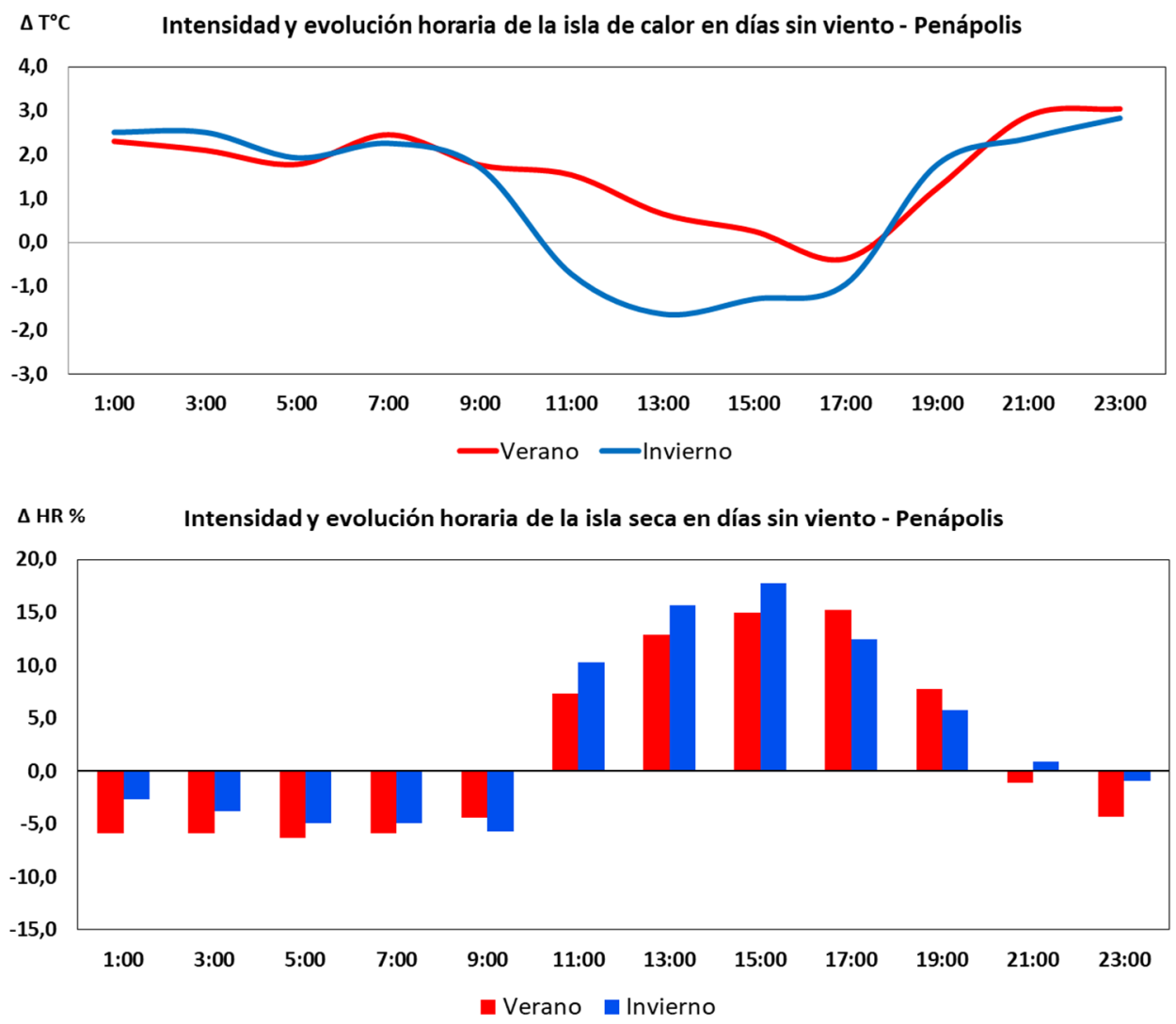

Figura 13- Intensidad y evolución horaria de la isla de calor y seca en verano e invierno en días sin viento - Penápolis. Fuente: Elaborado por los autores

En invierno la duración ha reducido, actuó desde las 19h hasta las 9h. Por lo tanto, en invierno hubo una isla de frescor más larga, que permaneció activa durante toda la tarde, especialmente desde las $11 \mathrm{~h}$ hasta las $17 \mathrm{~h}$, y con intensidad máxima a las $13 \mathrm{~h}$.

\section{Discusión}

Por lo tanto, bajo condiciones de estabilidad atmosférica, la isla de calor urbana alcanzó una intensidad media máxima de $3,5^{\circ} \mathrm{C}$ en el verano. Mientras que, bajo condiciones de 
inestabilidad de tiempo, la máxima registrada fue de $2,8^{\circ} \mathrm{C}$, también registrada en el verano. En lo que se refiere a la duración, en diciembre la isla de calor actuó prácticamente constante entre las $23 \mathrm{~h}$ y las $24 \mathrm{~h}$ de duración, mientras que en enero tuvo menor duración, entre las $21 \mathrm{~h}$ y las $24 \mathrm{~h}$. Julio y junio presentaron similitudes con las $15 \mathrm{~h}$ y las $16 \mathrm{~h}$ de duración.

En lo que respecta a las intensidades, de manera general, se puede afirmar que los mayores valores de la isla de calor ocurrieron por la noche y la madrugada con excepción de diciembre, que tuvo un patrón distinto y presentó en días sin lluvia y en días con viento la mayor intensidad a las 9h. Todos los otros meses estudiados presentaron máxima intensidad a las $23 \mathrm{~h}$ y a la $1 \mathrm{~h}$ o en ambos horarios.

La isla de frescor tuvo una actuación bastante débil durante el verano, siendo inexistente en diciembre y poco expresiva en enero, con intensidades menores de $-0,5^{\circ} \mathrm{C}$. En el invierno su duración e intensidades fueron más elevadas, principalmente en días con viento, con inicio a las $11 \mathrm{~h}$ y finalización a las $17 \mathrm{~h}$.

La presencia de la isla de frescor en ese período del día, especialmente en invierno, es explicada por las características de uso y cobertura de la tierra rural en ese período, cuando la vegetación de la zona rural disminuyó considerablemente en virtud del período de estiaje y de la cosecha de la caña, presentando así mucho suelo expuesto. Es importante recordar que el suelo expuesto tiene mayor capacidad de calefacción que los materiales constructivos urbanos, por lo tanto, fue capaz de calentarse más durante el día y a su vez calentar el aire en la zona rural.

Sin embargo, así como el suelo expuesto gana calor más rápidamente comparado a los materiales constructivos urbanos, también pierde calor con mayor rapidez que las áreas urbanas. Luego a las $19 \mathrm{~h}$, la zona rural se encontraba menos calentada que la ciudad, configurando así el horario de inicio de la isla de calor, que de manera general, actuó de las $19 \mathrm{~h}$ a las $9 \mathrm{~h}$.

Con relación a la isla seca se observaron mayores similitudes entre los meses y las estaciones y hasta mismo entre los días con viento, sin viento y sin lluvia. En síntesis, la isla seca estuvo presente en el período nocturno y en las primeras horas de la mañana, con inicio a las $23 \mathrm{~h}$ y término a las $9 \mathrm{~h}$. Su máxima intensidad aconteció en diciembre en días sin 
Iluvia con $-9,4 \%$ a las $7 \mathrm{~h}$. Los días con Iluvia fueron excepciones, pues en el invierno no hubo la formación de islas secas en ningún horario del día.

Las islas húmedas ocurrieron por la tarde e inicio de la noche, entre las $11 \mathrm{~h}$ y $21 \mathrm{~h}$, pero en algunos días su término fue adelantado para las $19 \mathrm{~h}$ o atrasado para las $23 \mathrm{~h}$. Lo que escapó a ese patrón fueron los días con lluvia, que presentaron islas húmedas durante todas las horas del día en los meses de junio y junio (invierno). Su máxima intensidad de $20 \%$ ocurrió en días sin lluvia a las $15 \mathrm{~h}$ en el mes de junio. Por lo demás, ese horario representó en todos los análisis las mayores expresividades de la isla húmeda, presentando siempre las mayores intensidades del día.

La variación y evolución de la isla seca y húmeda está directamente relacionada con la isla de calor y fresca, ya que la humedad relativa del aire es una grandeza inversamente proporcional el punto de saturación del vapor, en consecuencia, es dependiente de la temperatura del aire (MENDONÇA, DANNI-OLIVEIRA, 2007). Por lo tanto, las islas de calor y seca correspondieron en variabilidad horaria, las dos actuaron concomitantemente en la zona urbana, principalmente en días de estabilidad atmosférica (días sin viento y días sin Iluvia). Además, se resalta que ambas también tuvieron sus intensidades máximas en el mes de diciembre (verano) que aliada a una duración de $24 \mathrm{~h}$ de isla de calor, también identificada en ese mes, indica una situación agravante a la calidad de vida de los citadinos, una vez que las molestias térmicas naturalmente causadas en el ambiente tropical en esa estación fueron potenciadas por la presencia de estos fenómenos.

Luego, se verificó que en Penápolis los efectos de las islas de calor y seca son minimizados por la mañana y por la tarde, sobre todo a las $17 \mathrm{~h}$, cuando la temperatura urbana es similar o más baja que la rural. Esta característica de la disminución en la isla de calor cerca de la salida y puesta de sol también fue encontrada en estudio realizado en Basel, Switzerland (PARLOW; VOGT; FEIGENWINTER, 2014). Este fato también pude estar relacionado a las diferencias en las características térmicas de las superficies urbanas e rurales, que como mencionado anteriormente tienen ritmo de calefacción y enfriamiento diferentes y al efecto sombra causado por la baja incidencia e inclinación de los rayos solares.

Por lo que se refiere a las condiciones meteorológicas, la precipitación fue el elemento de mayor influencia en la dinámica atmosférica, una vez que en los días con lluvia se 
registraron las menores intensidades de las islas de calor. La cobertura de nubes ejerce control sobre las ondas cortas y los intercambios de olas largas; los principales impulsores de calefacción y enfriamiento, respectivamente. Por lo tanto, la nebulosidad causa la reducción de la radiación solar y mayor homogenización de las condiciones atmosféricas entre el ambiente rural y urbano, y por lo tanto, es un fuerte factor para la disminución de la isla de calor urbana (OKE et al., 2017).

Por fin, se ha notado que fue los días sin viento que resultaron las mayores intensidades, eso porque aunque la isla de calor es directamente ligada a la estructura urbana, sino que también es moldeada por la dirección de los vientos. Los efectos de advección y mezcla de los vientos producen inyección de aire más frío en la ciudad o escape de aire más caliente de la ciudad para el área rural. Por lo tanto, la dispersión del calor causa la disminución de las diferencias de temperatura del aire, y consecuentemente, de la intensidad de la isla de calor. Por otro lado, en condiciones de viento calmo hay la situación ideal para la dispersión y pérdida de calor entre la superficie y la baja atmósfera sin la acción de la turbulencia, consecuentemente, en esos días se acentúan las diferencias entre las áreas urbanas y rurales (OKE et al., 2017).

\section{Conclusiones}

Este estudio ha demostrado que el proceso de urbanización en Penápolis, así como ocurrió en la mayoría de las ciudades brasileñas, modificó las propiedades meteorológicas del aire urbano con el incremento de la temperatura y decrecimiento de la humedad relativa en las áreas urbanizadas, configurando así el "clima urbano".

Con la intensidad media máxima de $3,5^{\circ} \mathrm{C}$ los datos indicaron la existencia de una isla de calor de magnitud moderada (FERNÁNDEZ GARCÍA, 1996), con pico de mayor fuerza por la noche y débil actuación durante la tarde, pero su intensidad quedó condicionada a las condiciones atmosféricas, con caída en los días de inestabilidad atmosférica.

Entre las medidas mitigadoras para amenizar el cuadro de incomodidad térmica en la ciudad pueden mencionarse las acciones de planificación y gestión, que prioricen los beneficios que trae la vegetación, como por ejemplo el aumento de la arborización de las vías, la 
implementación de áreas verdes y la revitalización de las que ya existen, la sustitución por coberturas frescas y medidas en relación al uso y cobertura de la tierra, fundamentalmente en el sentido de la fiscalización de la ocupación, para que la tasa de ocupación no sobrepase los valores establecidos y para que las exigencias de construcción sean respetadas.

También, es fundamental la creación por parte del poder público de espacios libres de edificación, como áreas recreativas, áreas verdes y parques públicos, que compensan el calor generado en algunos sectores y evitan la intensificación de la ocupación. Esas medidas mitigadoras podrían ser fácilmente aplicadas en Penápolis, una vez que su pequeño tamaño poblacional colabora para acciones de planificación ambiental urbana.

\section{Agradecimientos}

A la "Fundação de Amparo à Pesquisa do Estado de São Paulo" (FAPESP) por el apoyo financiero, los procesos no 2015/19319-2 y no 2014/05824-4.

\section{Referencias bibliográficas}

AMORIM, M. C. C. T. O clima urbano de Presidente Prudente/SP. (Tese de Doutorado em Geografia) Faculdade de Filosofia, Letras e Ciências Humanas, Universidade de São Paulo, São Paulo. 2000, $374 \mathrm{f}$.

AMORIM, M. C. C. T. Intensidade e forma da ilha de calor urbana em Presidente Prudente/SP. Geosul, v. 20, n. 39, p. 65-82, 2005.

AMORIM, M. C. C. T. Climatologia e gestão do espaço urbano. Mercator, v. 9, número especial, p. 71-90, 2010.

AMORIM, M. C. C. T.; DUBREUIL, V. Intensity of Urban Heat Islands in Tropical and Temperate Climates. Climate, v. 5, p. 91-104, 2017.

BRANDÃO, A. M. de P. M. O Clima Urbano da cidade do Rio de Janeiro. (Tese de Doutorado em Geografia) - Faculdade de Filosofia, Letras e Ciências Humanas, Universidade de São Paulo, São Paulo. 1996, $362 f$.

FERNÁNDEZ GARCÍA, F. Manual de climatología aplicada: clima, medio ambiente y planificación. Madrid: Editorial síntesis, S.A., 1996. 285p.

ONU-HABITAT. PROGRAMA DAS NAÇÕES UNIDAS PARA OS ASSENTAMENTOS HUMANOS. Informe "World cities 2016". Disponible en: <http://wcr.unhabitat.org/wp-content/uploads/sites/16/2016/05/Chapter-1-WCR2016.pdf>, acceso en 26 de sep. 2016.

UNUBR. NAÇÕES UNIDAS NO BRASIL. Informe 'Fato sobre as cidades'. Producido por el Departamento de Información Pública de las Naciones Unidas, junio de 2012. Disponible en: < http://www.onu.org.br/rio20/cidades.pdf >, acceso en: 06 feb. 2016.

ONU-HABITAT. PROGRAMA DAS NAÇÕES UNIDAS PARA OS ASSENTAMENTOS HUMANOS. Informe "Estado das Cidades da Latina e Caribe". Disponible en: <http://www.onuhabitat.org/index.php?option=com_docman\&task=cat_view\&gid=362\&Itemid=18>, acceso en: 06 feb. 2016. 
IBGE. INSTITUTO BRASILEIRO DE GEOGRAFIA E ESTATÍSTICA. População estimada 2017. Disponible en: <https://cidades.ibge.gov.br/brasil/sp/penapolis/panorama>, acceso en: 10 de jan. 2018.

LOMBARDO, M. A. Ilha de calor nas Metrópoles: O exemplo de São Paulo. São Paulo: Hucitec, 1985. 244p.

MENDONÇA, F. A. O Clima e o planejamento urbano de cidade de porte média e pequeno: preposição metodológica para estudo e aplicação à cidade de Londrina, PR. (Doutorado em Geografia Física). - Faculdade de Filosofia, Letras e Ciências Humanas, Universidade de São Paulo, São Paulo. 1994, 322p.

MENDONÇA, F. A. Clima e Planejamento urbano em Londrina. In: Monteiro, C. A de F; Mendonça, F. A (Org.). O Clima Urbano. São Paulo: Contexto, 2009. p. 93-120.

MENDONÇA, F.; DANNI-OLIVEIRA, I. M. Climatologia: noções básicas e climas do Brasil. São Paulo: Oficina de Textos, 2007, 206p.

MOREIRA, J. L.; AMORIM, M. C. C. T. O clima urbano de Penápolis, São Paulo, através da temperatura da superfície e de índices radiométricos. Geosaberes: revista de estudos geoeducacionais, jul. 2015, v. 6, n. 3, p. $190-202$.

OKE, T. R. The energetic basis of the urban heat island. Quarterly Journal of the Royal Meteorological Society, Londres, 1982, v. 108, n. 455, p. 1-24.

OKE, T. R. Boundary Layer Climates. (2a. ed.). Londres: Routledge, 1987.

OKE, T. R.; MILLS, G.; CHRISTEN, A.; VOOGT, J. A. Urban Climates. Cambrigde: Cambrigde University Press, 2017.

PARLOW, E.; VOGT, R.; FEIGENWINTER, C. The urban heat island of Basel - Seen from different perspectives. Die Erde; Zeitschrift der Gesellschaft für Erdkunde zu Berlin. 145. 1-2. 10.12854/erde-145-8.

PORANGABA, G. F. O; AMORIM, M. C. C. T. Análise de ilhas de calor diagnosticas por meio de transectos móveis em Assis, Cândido Mota, Maracaí e Tarumã (SP). CONFINS (PARIS), 2017, v. 33, p. 1-20.

RAMPAZZO, C. R.; SANT'ANNA NETO, J. L. Clima e qualidade ambiental urbana em Alfredo Marcondes/SP: análise em episódio de inverno. Revista Geonorte, [S.I.], 2012, v. 3, n. 9, p. 194- 206.

SANTOS, M. A urbanização brasileira. São Paulo: EDUSP, 2009.

SCARLATO, F. C. População e urbanização brasileira. In: ROSS, J. L. S. (Org.). Geografia do Brasil. 6. ed. São Paulo: Edusp, 2009. p. 381-463.

SILVA, L.T.; TOMMASELLI, J.T.G.; AMORIM, M. C. C. T. O clima urbano de Penápolis-SP: um episódio de inverno. In: João Lima Sant'Anna Neto. (Org.). Os climas das cidades brasileiras. Presidente Prudente: UNESP/FCT/Programa de Pós-graduação em Geografia, 2002, p.197-227.

TARIFA, J. R. Análise comparativa da temperatura e umidade na área urbana e rural de São José dos Campos (SP). Geografia, v. 2, n. 4, p. 59-80, 1977.

TEIXEIRA, D. C. F.; AMORIM, M. C. C. T. Perfil térmico noturno de cidade pequena do ambiente tropical em episódios de inverno. RA'E GA (UFPR), 2016, v. 36, p. 208-228. 